\title{
LETHALITY OF ELECTROMAGNETIC FIELD IN ELECTRIC POWER DISTRIBUTION NETWORKS: CAPACITIVE EFFECT
}

\author{
Paul I. Audu ${ }^{1}$ \\ ${ }^{1}$ Power System Consultant, Pauma Engineering Consultants, Kaduna, Kaduna State, Nigeria
}

\begin{abstract}
Several cases of electrocution incidences experienced on active duty by staff of the Power Industry and Vandals of electrical facilities have resulted from Electromagnetic Field Induction. These usually emanate from ignorance or careless application of basic rules of electricity at new installations, maintenance and system expansions or network integration. Most of these situations result from undue neglect of statutory clearances and approach distance rules, improper network evaluation as well as blatant disregard to the subject of electrical safety. We will be looking at one unfortunate incident of a man electrocuted in Kaduna, and technically evaluating the attendant safety issues involved. Issues involving electromagnetic field effect and its consequences on this case-study is investigated from three premises using electrostatic techniques relating to this phenomenon, based on data of measured values collated from typical sites. The first premise is the consideration of the human anatomy response in the presence of electric and magnetic fields as it affects. The second consideration appraises the interaction of the human body impedances with electromagnetic field on direct contact (with or without Personal Protective Equipment - PPE) as well as impact of electric and magnetic field without direct contacts in the process of electrocution. Conclusions are drawn from charts, tables and excel calculation sheets derived from relevant engineering relationships
\end{abstract}

Keywords: - Electric Fields, Magnetic Fields, Statutory Clearances, Approach Distance, Electrostatic Induction, Electromagnetic Induction, Induced Voltage, Capacitive Networks and Dielectric Material.

\section{WORKING IN ELECTROMAGNETIC FIELD ENVIRONMENT}

Nature of electrical accidents reveal the underlying cause to be a combination of three possible factors: work involving unsafe equipment and installations; workplaces made unsafe by the environment; and unsafe work practice.

Therefore, electrical hazards are characterized by:

1. UNSAFE CONDITIONS - equipment/installation and environment

2. UNSAFE WORK PRACTICE - work performance or attitude

3. COMBINATION OF THE TWO

Working on equipment in a de-energized state is required unless de-energizing introduces an increased hazard or is infeasible. This write-up is designed to help ensure that energized electrical work in the Power Industry is performed safely by qualified electrical workers, who are trained and provided with the appropriate safe.

work procedures, protective equipment and other controls. The write-up is intended to give insight to protect employees against electrical shock, burns and other potential electrical safety hazards as well as comply with regulatory requirements.
The Nigerian Electricity Regulatory Commission (NERC) has said that about 162 electrocutions and 132 injuries, all induced by poor safety regulations and compliance were recorded in the Nigerian Electricity Supply Industry (NESI) in 19 months (between January 2012 and July 2013), mostly at various electricity distribution companies. This is on the average nine (9) deaths and seven (7) injuries per month. It is obvious that this trend has continued unabated and on the increase because of non-conformance of electricity distribution companies (DISCOs).

\subsection{Work on High-Voltage Systems}

Any work on high-voltage equipment and power systems must be performed by qualified and authorized workers in accordance with written safe work procedures acceptable to the NERC. Requirements for working on these systems are set out in the Nigerian Electricity Health and Safety Standards (Section 2) and Occupational Health and Safety Regulation, Part 19. For isolation and lockout, workers must follow the safe work procedures set out by the employer and/or the owner of the power system.

Accidents involving high voltages can result in severe injuries and death. When electric current passes through the body, it generates heat and can extensively damage internal tissues. In some cases, the entry and exit wounds are so severe that a foot or hand has to be amputated. The electric current can also stop the heart. 
Electrical workers are frequently in close proximity to energized parts where power arcs can occur. It is not necessary to touch an energized conductor to receive an electrical shock. Qualified electrical workers shall be aware of the final established flash boundary distance as well as the shock protection distances and ensure that unprotected persons near the work area are not allowed to cross the greater distance of the two. This is the shock protection distance from a live part within which (limited space) only a "Qualified Person" may work.

We will now take a look at the various electrocution incidents in recent time and analyze them vis-à-vis the relevant safety standards, evaluate areas of violations and propose solutions to guard against re-occurrence.

\subsection{HV/LV Overhead Network Configurations}

Most often, workers and vandals tend to overlook some very critical electrical characteristics of this type of network because we are so much in a hurry to accomplish the work without due attention to safety situations peculiar to this type of arrangement. In some cases, it is due to lack of proper training or education.

\subsubsection{Recognizing the Hazards}

Attending to a dual-voltage network of this form involves:

1. A careful study of interconnecting circuits and interlocks to be painstakingly employed to understand what the risks are in particular network we are workingon and remove danger of electrocution in some cases.

2. Taking all necessary steps and precautions peculiar to electrical distribution equipment or network in accordance with statutory requirements and procedures for removing electrical hazards.

Unless, and until these risks and dangers are recognized and removed or properly addressed, it will always be dangerous to carry out any maintenance or construction work.

\section{CASE-STUDY REPORT: MAN}

\section{ELECTROCUTED TRYING TO REMOVE LV ELECTRIC CABLE}

It was reported that an unidentified middle age man was electrocuted at the early hours of Sunday, $27^{\text {th }}$ December 2015 while trying to steal electric cable at a power supply installation in Kaduna. The cable in question was a $150 \mathrm{~mm}^{2}$ 4-core up-riser cable at the distribution substation along Accra Crescent, UngwarRimi, Kaduna.

From the cable configuration (4-core) in a distribution substation, it must be a Low Voltage Outgoing cable from a unit of the feeder-pillar. The Google geographical map of the area in question is illustrated in figure 1 below. It is assumed that the $11 \mathrm{KV}$ feeder radiated from Dawaki Road Substation, which is about two kilometers $(2 \mathrm{Km})$ away. The data obtained from this layout shall be used for our network analysis.

The graphic picture is shown in figure 2 below. Three obvious scenarios can be visualized here:

a) The fellow neatly removed the feeder-pillar fuses to disconnect the incoming end so as to free it from source of power supply, not minding the danger posed by the nearby $11 \mathrm{KV}$ Overhead Line.

b) Causes an unscheduled emergency outage on the $11 \mathrm{KV}$ incoming supply to the substation, knowing that customers would not in anyway, be surprised or that supply authority will not be in a hurry to restore. He then embarks on step (a) above.

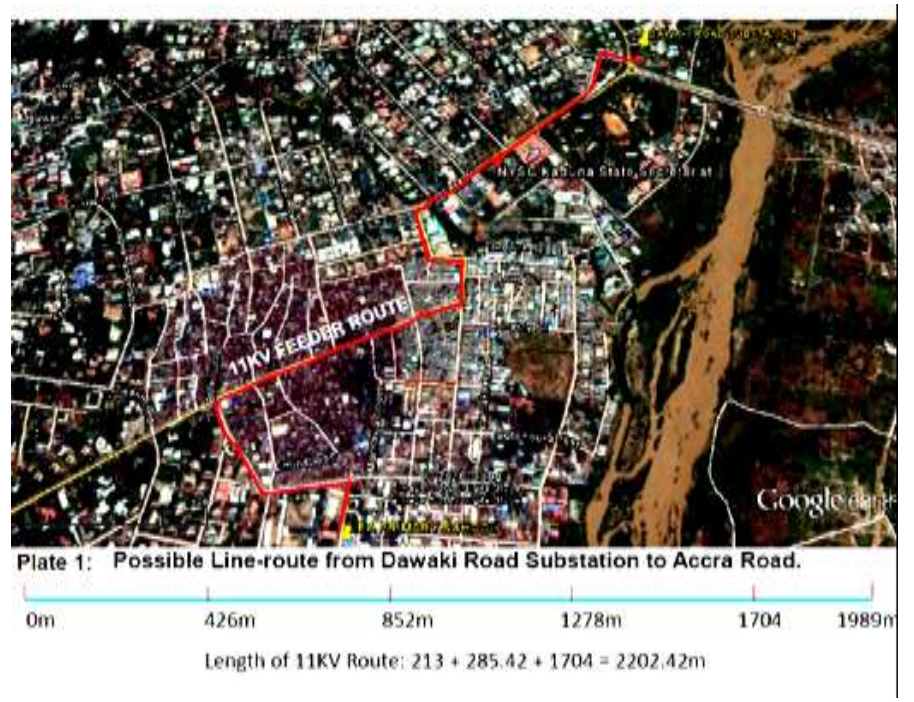

Fig 1: 11KV Line Route from Dawaki Road Substation

c) The vandal confidently goes to the pole end to disconnect the cable from the pole comprising $\mathrm{HV} / \mathrm{LV}$ configuration with his hand gloves, assuming only the dangers of the $\mathrm{LV}$ circuits as shown in figure 3 below.

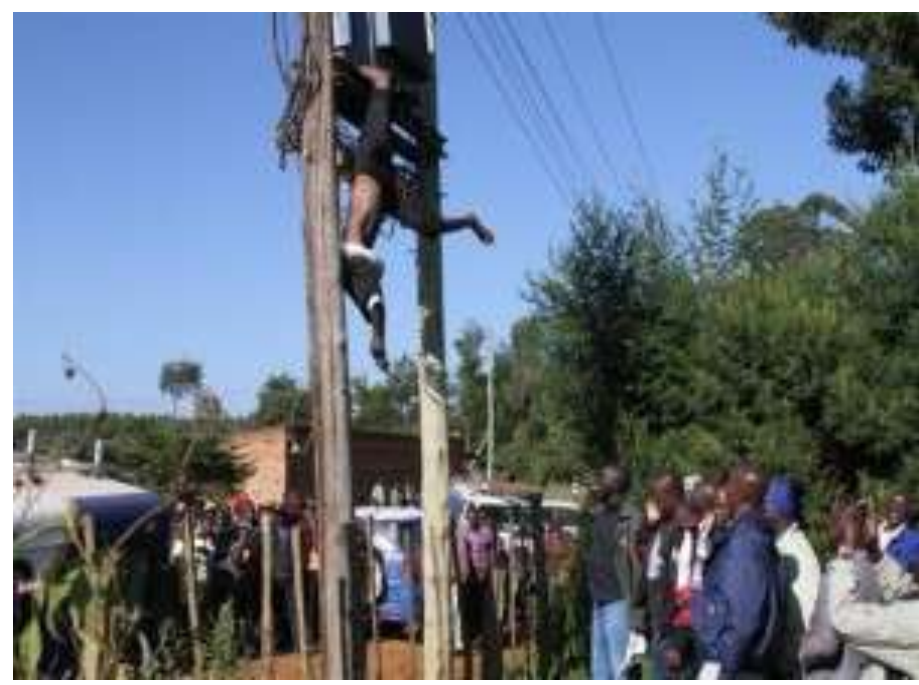

Fig 2: Victim of electrocution falling off the Pole 
It must be noted here that maintenance of Statutory Approach Clearance Limit cannot be guaranteed in this kind of scenario.

\subsubsection{Electromagnetic Field Evaluation and Analysis}

A higher-voltage distribution level circuit may feed several lower-voltage distribution circuits through transformers. If the higher voltage circuit is de-energized, and if lowervoltage circuits connected remain energized through other sources, the higher voltage circuit will remain energized.

We will assume here that the transformer LV is completely isolated through the HV drop-out fuses.

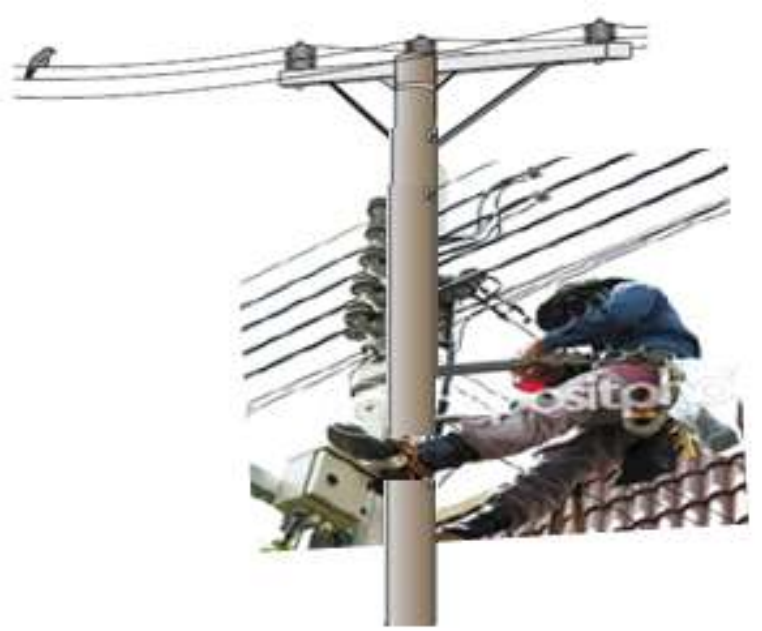

Fig 3: HV/LV Line Configurations

Another problem can arise when de-energized wires become energized through electrostatic or electro-magnetic induction from energized wires in close proximity. It is therefore possible that a person working on a high or low voltage lines close to other energized lines could get electrocuted.

On medium and high voltage level, if the approach clearance limit is violated, electrostatic or electromagnetic induction could result to electrocution.

Two basic phenomena are prevalent in electromagnetic induction with reference to electrocution:

1. The power frequency electric field induced currents in the body (eddy current) as well as charges on its surface.

2. Magnetic induction: The current induced in the body by magnetic field are greatest near the periphery of the body and smallest at the center of the body.

The field lines through the human body is illustrated in figure 4 below [9].

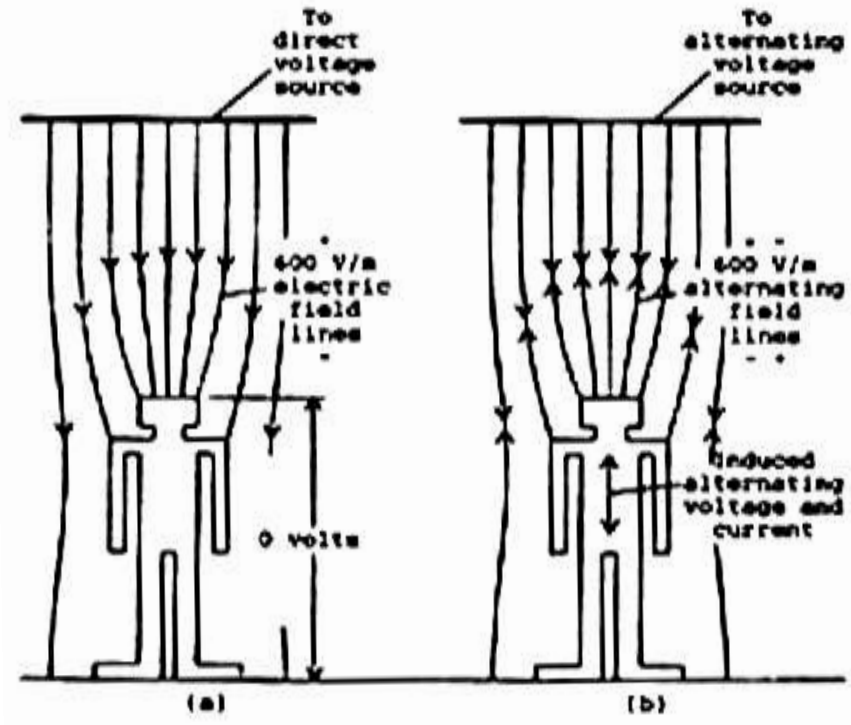

Direct electric field link Magnetic field induced Voltage

Fig 4: Illustration of Field lines through human body

The main effects of the electromagnetic field are summarized as follows:

$>$ Magnetic field induces a voltage in the tissue of human body, which causes a current to flow through it due to its conductivity.

$>$ The magnetic field has the influence on the tissues of the human body, these maybe beneficial or harmful depending upon the nature.

$>$ The magnitude of the surface charge and internal body currents by any given source of power frequency depends upon many factors. For example, this includes magnitude of the currents and charges in the source, the distance of the body from the source, the presence of other objects that might shield or concentrate the field and the body posture, shape, and orientation. For this reason, the surface charges and the currents, which a given field induces are very different for different for different human beings.

$>$ When a person who is isolated from the ground by some insulating material, comes in close quarters to an overhead transmission line, and electrostatic field is set up in the body of the human being whose ordinary resistance is about $2000 \Omega$. When the same person touches the grounded object, it will discharge through his body causing a large current to flow through the body. Discharge currents from $50 \mathrm{~Hz}$ electromagnetic field are weaker than natural currents.

$>$ For human beings the limit of the undisturbed field is $15 \mathrm{kV} / \mathrm{m}$ RMS to experience possible shock.

The human body is a very good conductor. Therefore, when you stand in an electromagnetic field, you become an antenna and are not even aware of it. EMFs, or electromagnetic fields, are created whenever a voltage or a current is present. Electrical current produces a magnetic field, while voltages produce and electric field. 
According to Nigerian Electricity Supply and Installation Standards Regulations (NESIS) 2015 section 3.6.1(c), The minimum clearance between the nearest conductors of different circuits at the point of crossing, including "aerial" earth wire, are well defined on table 3.6.1 PLUS the maximum design sag of the conductor of the lower circuit at the point of crossing.

Columns 6, 7 and Row 5 in Table 3.6.1 of the table falls within the values under consideration for $33 / 11 / 0.415 \mathrm{KV}$ power distribution systems as applicable to Nigeria.

Figure 5 illustrates the HV/LV pole configuration obtainable in Nigeria, similar to the one under consideration. Electromagnetic Field interferences are avoided as long as the statutory clearance limits are maintained.

It is not unlikely that the victim had earlier disconnected the Low Voltage network whose cable he planned to vandalize. This is a case of double circuit overhead power lines having a passive circuit and an active one. It will be worth noting that it may be necessary to consider determining the induced voltages by the active circuit into the disconnected one.

Electromagnetic fields of low frequency $(50 \mathrm{~Hz})$ created by the overhead power transport and distribution lines affect good working and service of all electrical equipment placed nearby,and they could also produce some unwanted effects on the biological organisms located in that area.

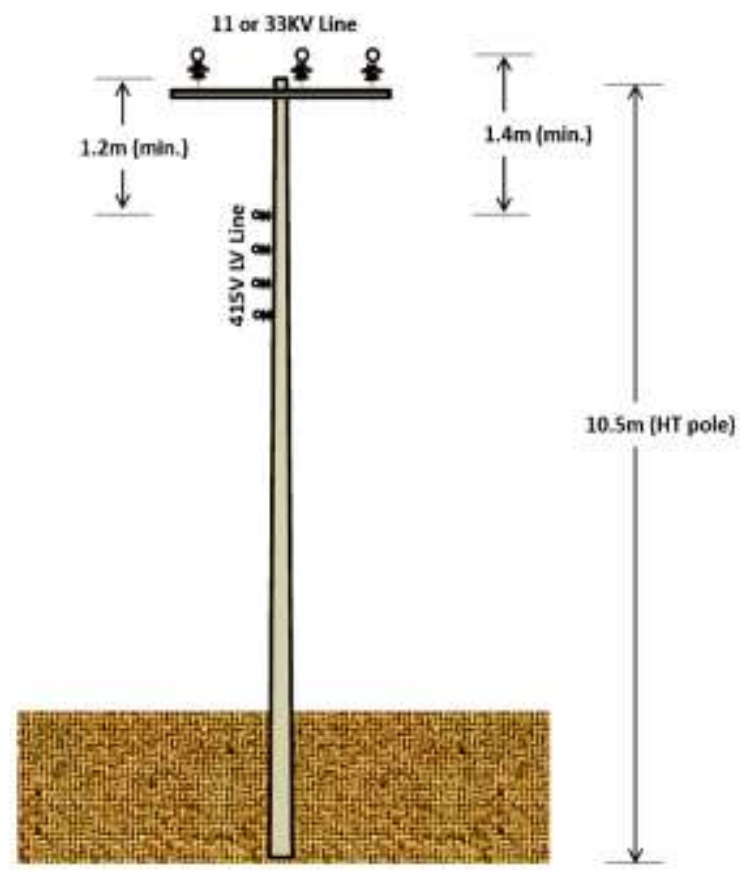

Fig 5: Typical HV/LV Power Line Configuration

As noted earlier, the electro-magnetic disturbance field interferences produce two different types of influences on all the objects located in that area (including the nearby electric lines), namely:
- Electric influences produced by capacitive connections(or couplings) between the phase conductors of the three phase overhead power lines and the nearby objects or electrical lines;

- Magnetic influences realized by inductive couplings between the loops of the parallel and adjacent circuits formed by the conductors and the earth.

All these influences are physically reflected on the voltage levels induced by the capacitive or inductive connections in the nearby electrical circuits, on the electric field intensity or potential from the earth, and on the value of the magnetic induction at different points, located near the power mains.

Knowing, as accurate as possible, these electro-magnetic parameters, especially those of the voltages induced in capacitive couplings, as well as magnetic effect, will help us to search for methods and techniques that will enable us to reduce the unwanted effects and to increase the protection of the working staff.

Regardless the type of electromagnetic coupling, the values of induced voltages depend on the geometry of electrical lines, and on the loads transported through them. Our interest in this consideration is the capacitive couplings that produce the induced voltages responsible for electrocution.

In the case of capacitive coupling, the electric line with double circuit represents a complex set of capacitors that are formed due to the differences in potential both between the active circuit phases, and the active circuit conductors and those of the passive circuits insulated from the ground. The point of Electric Field influence for this case and the simplified set of capacitors that are formed are shown in Figure 6 , with respect to one passive phase with which the victim was in contact.

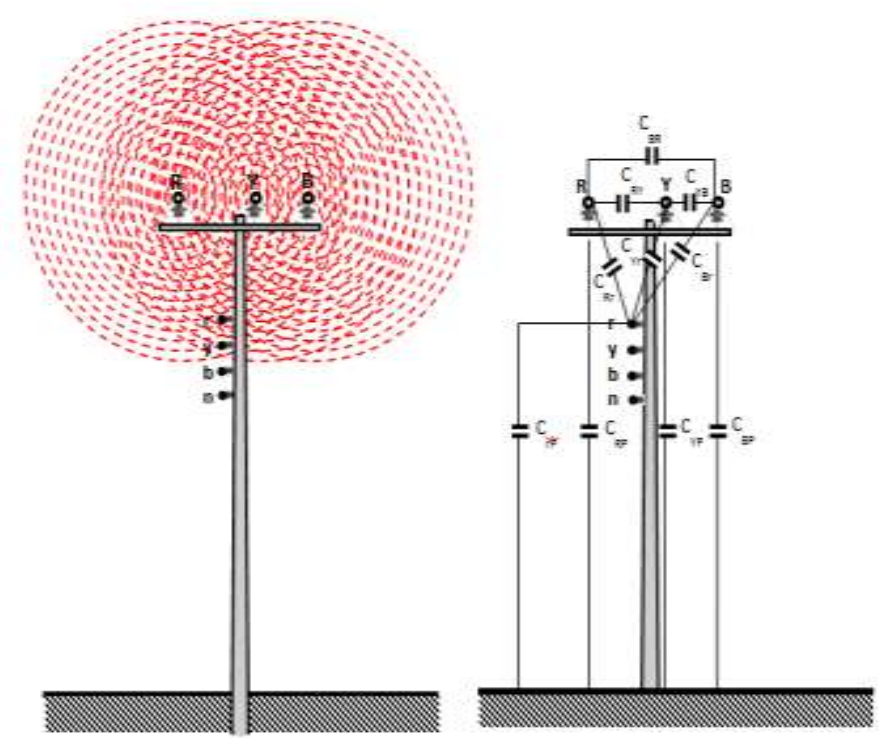

Fig 6: Electric Field Influence/Capacitances between 11 or $33 \mathrm{KV} \mathrm{HV}$ line and $415 \mathrm{~V}$ 
Representing the entire phase-phase and active line-topassive line couplings for the entire configuration will require evolving a complex mathematical model that would be developed for computer simulation. This is beyond the scope of this book. However, it would suffice to know that the electrocution of the victim must have occurred when he was in contact with one of the four low voltage lines (phase or neutral). We will assume the Red Phase in this consideration.

If the human body, being an active electromagnetic material as discussed above bridges the gap, there will be flow of current and it could rise sufficiently to cause electrocution. This is illustrated in figure 7.

To evaluate the inductive effect of this incidence, we shall consider the equivalent circuit[1] of figure 9 , which, is the electrical network representing illustrations of figures 7 and 8.

Here we shall assume points $\mathbf{O}$ and $\mathbf{O}^{\prime}$ as imaginary points of contact with floating earth through the concrete pole and Channel Iron Cross-arm as well as LV shackle bolts for HV

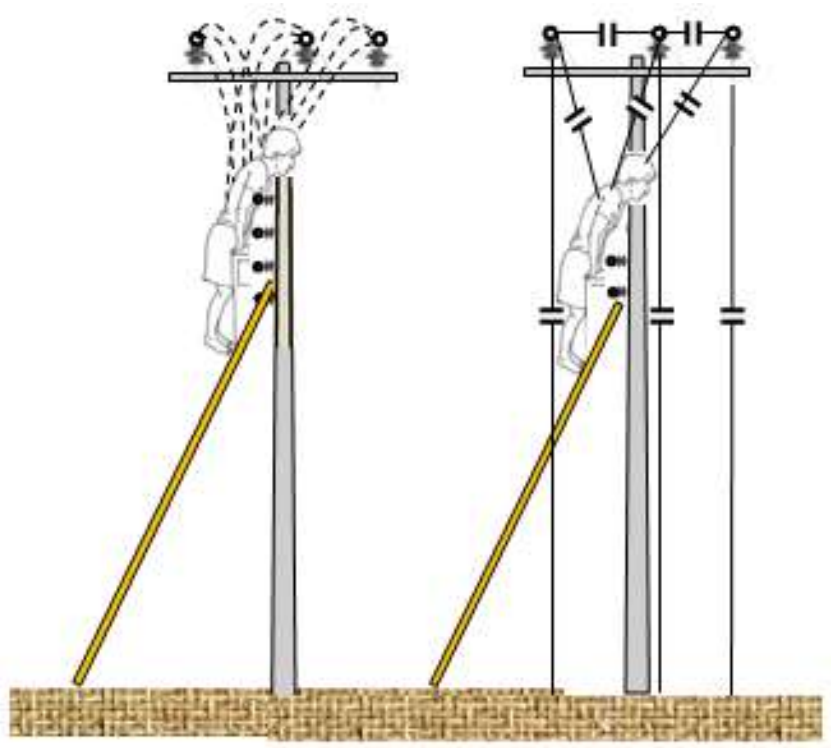

Fig 7: Effect of Induced Electric Field on Human

and LV terminals respectively. Point $\mathbf{P}$ is the actual hypothetical earth return terminal for both $\mathrm{HV}$ and LV live terminals

From the picture of figure 2 , it is obvious that the victim with average of height of 1.5-1.6m.must have gone half-way or more into the gap between the Medium Voltage line and the LV Network, with the clearance gap reduced by 0.8 metres.

The current source from active HV line shall be used as the drivingcurrent establishing the impedance produced by the capacitive network from the source.The optimized equivalent circuit is shown in figure 11 below, with the impedance network in figure 12 .

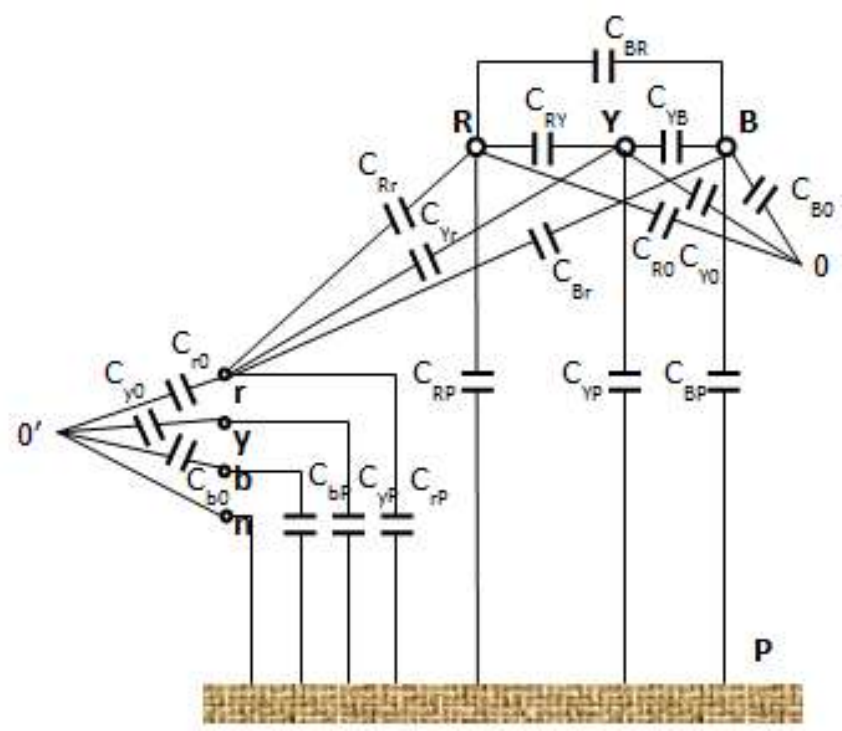

Fig 8: Capacitive Network between HV and LV

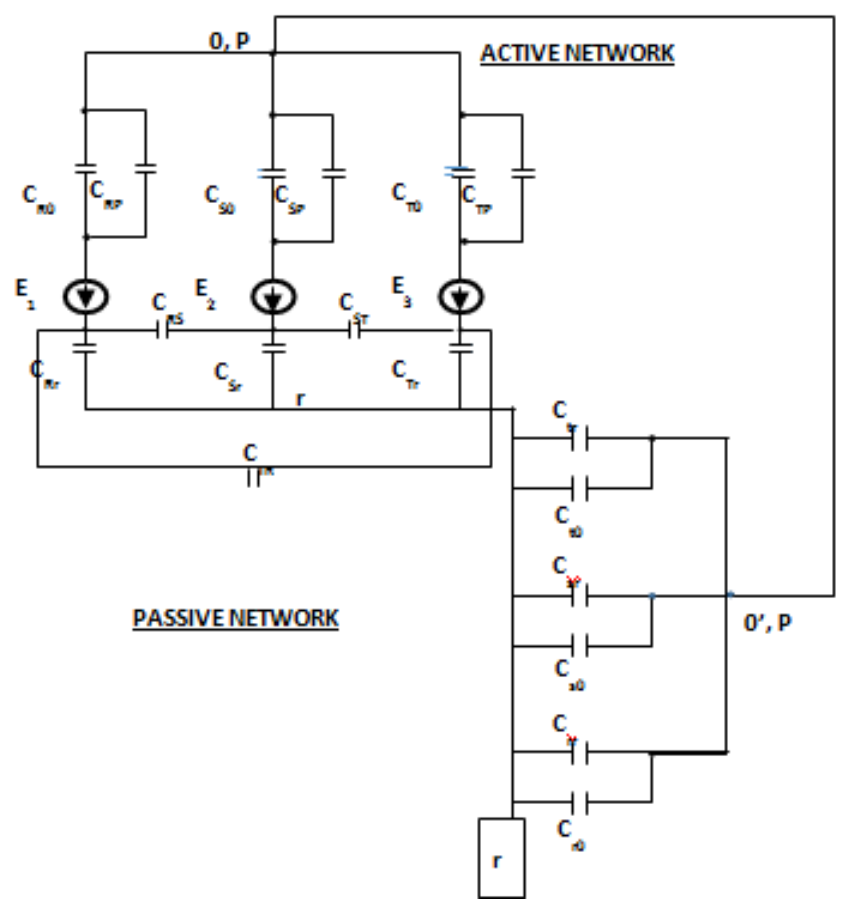

Fig 9: Equivalent Circuit of the Capacitive Network

Delta-star transformation was performed onthe HV/LV capacitive couplings of figure 9 and the resulting impedance network of figure 10 was established. 


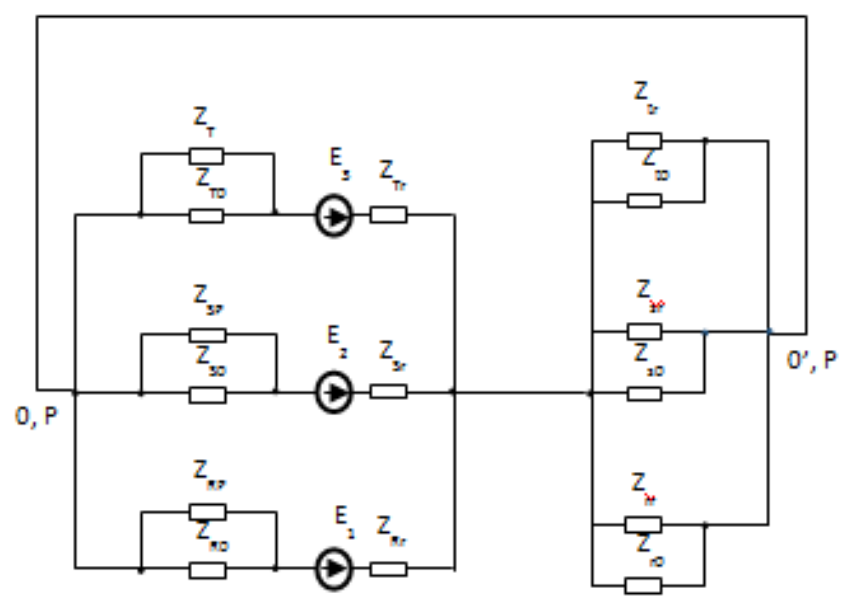

Fig 10: Equivalent Impedance Network

\subsubsection{Electric Circuit Analysis}

The values of the partial capacitances between phases and between phases and ground are calculated by the followig relations:

for the partial capacitances between phases:

$$
C_{i k}=\frac{2 \pi \varepsilon_{0} l}{\ln \frac{d_{i k}}{r_{0}}}
$$

for the partial capacitances between phases and ground:

$$
C_{p i}=\frac{2 \pi \varepsilon_{0} l}{\ln \left(\frac{2 h_{i}}{r_{0}}\right)}
$$

where: $l$ - the length of the line taken into account,

$d_{i k^{-}}$the distance between phase conductors, according to geometric dimensions of the lines

$r$ - the radius of the phase conductor (assume $\mathrm{a}=150 \mathrm{~mm}^{2}$ for both $\mathrm{HV}$ and LV).

Table 1 shows minimum clearances of electric lines obtainable in Nigeria at various voltage levels.
Table 1: Minimum Clearances of Electric lines at various Voltage Levels

\begin{tabular}{|l|l|l|l|}
\hline Voltage & $\begin{array}{l}\text { Normal } \\
\text { Equivalent } \\
\text { Span }\end{array}$ & $\begin{array}{l}\text { Phase to } \\
\text { Phase Clearance }\end{array}$ & $\begin{array}{l}\text { Phase to } \\
\text { Structures/Earth } \\
\text { Clearance }\end{array}$ \\
\hline 400 wolts & 45 metres & $200 \mathrm{~mm}$ & $25 \mathrm{~mm}$ \\
\hline 3,300 wolts & 45 metres & $400 \mathrm{~mm}$ & $130 \mathrm{~mm}$ \\
\hline 6,600 wol ts & 45 metres & $600 \mathrm{~mm}$ & $130 \mathrm{~mm}$ \\
\hline 11,000 volts & 90 metres & $700 \mathrm{~mm}$ & $180 \mathrm{~mm}$ \\
\hline 33,000 volts & 90 metres & $1,200 \mathrm{~mm}$ & $300 \mathrm{~mm}$ \\
\hline 66,000 volts & 190 metres & $1,800 \mathrm{~mm}$ & $600 \mathrm{~mm}$ \\
\hline 132,000 volts & 210 metres & $2,400 \mathrm{~mm}$ & $1,200 \mathrm{~mm}$ \\
\hline 330,000 volts & 450 metres & $600 \mathrm{~mm}$ & $2,400 \mathrm{~mm}$ \\
\hline 750,000 volts & & & \\
\hline
\end{tabular}

From table 1 above and figure 6(b) also reproduced in a close-up dimension of figure 11 below, assuming $11 \mathrm{KV}$ supply;

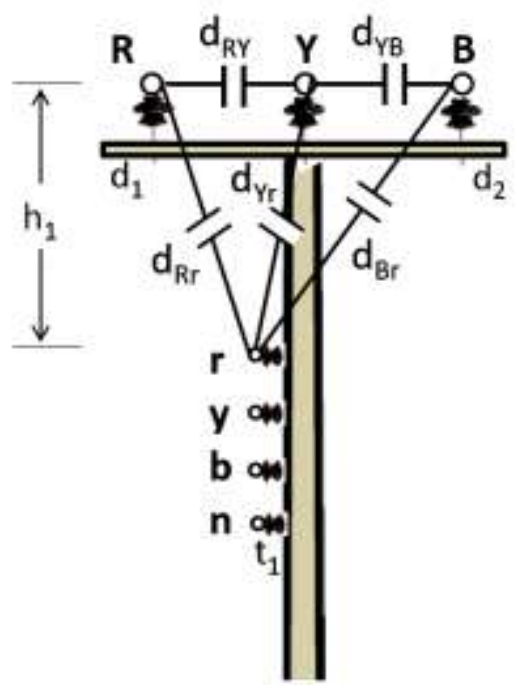

Fig 11: Close-up view of Capacitive Network Dimensions.

$\begin{array}{lllll}\mathrm{d}_{\mathrm{RY}} & = & \mathrm{d}_{\mathrm{YB}}= & 0.7 \mathrm{~m} \\ \mathrm{~d}_{\mathrm{ry}} & = & \mathrm{d}_{\mathrm{yb}}= & \mathrm{d}_{\mathrm{bn}} \\ & = & 0.2 \mathrm{~m} & & \\ \mathrm{~h}_{1} & = & 1.4 \mathrm{~m} & & \end{array}$

where, $\mathrm{h}_{1}$ - vertical clearance between $\mathrm{HV}$ and $\mathrm{LV}$ conductors

$\mathrm{d}_{\mathrm{ij}}=$ clearance between phases

$\mathrm{l}=2.202 \mathrm{~km}$ (approximate length of the $11 \mathrm{KV}$ line from Dawaki Road Substation to Accra Road, U/Rimi)

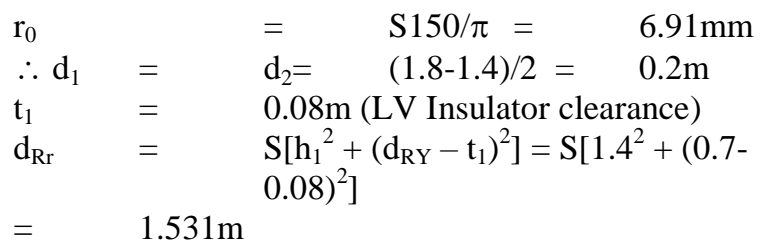




$$
\begin{aligned}
& \mathrm{d}_{\mathrm{Yr}}=\quad \mathrm{S}\left[\mathrm{h}_{1}{ }^{2}+\mathrm{t}_{1}{ }^{2}\right]=\quad \mathrm{S}\left[1.4^{2}+0.08^{2}\right]= \\
& 1.402 \mathrm{~m} \\
& \mathrm{~d}_{\mathrm{Br}}=\quad \mathrm{S}\left[\mathrm{h}_{1}^{2}+\left(\mathrm{d}_{\mathrm{YB}}+\mathrm{t}_{1}\right)^{2}\right]=\mathrm{S}\left[1.4^{2}+(0.7+0.08)^{2}\right] \\
& =\quad 1.603 \mathrm{~m} \\
& \mathrm{~h}_{\mathrm{i}}=(10.5-2)+(1.4-1.2) \quad=8.7 \mathrm{~m}
\end{aligned}
$$

\section{At Safe Minimum Distance}

Taking the safe limit allowable by law,

$$
\begin{array}{llll}
\mathrm{h}_{1}= & \mathrm{h}_{11}= & (1.4-0.8) \mathrm{m}= & 0.6 \mathrm{~m} \\
\therefore \mathrm{d}_{\mathrm{Rr}} & = & \mathrm{S}\left[\mathrm{h}_{11}^{2}+\left(\mathrm{d}_{\mathrm{RY}}-\mathrm{t}_{1}\right)^{2}\right]=\mathrm{S}\left[0.6^{2}+(0.7-0.08)^{2}\right] \\
& = & 0.863 \mathrm{~m} & \\
\mathrm{~d}_{\mathrm{Yr}} & = & \mathrm{S}\left[\mathrm{h}_{11}^{2}+\mathrm{t}_{1}{ }^{2}\right]= & \mathrm{S}\left[0.6^{2}+0.08^{2}\right] \\
& = & 0.605 \mathrm{~m} & \\
\mathrm{~d}_{\mathrm{Br}} & = & \mathrm{S}\left[\mathrm{h}_{11}^{2}+\left(\mathrm{d}_{\mathrm{YB}}+\mathrm{t}_{1}\right)^{2}\right]=\mathrm{S}\left[0.6^{2}+(0.7+0.08)^{2}\right] \\
& = & 0.984 \mathrm{~m}
\end{array}
$$

The evaluated Impedances are shown on tables $2 \& 3$ below.
Re-arranging re-evaluating the impedance diagram of figure 10 we have the configuration of figure 12. Figure 12(a) illustrates situation before and figure 12(b) during the electrocution incidence. It is worth noting from figure 7 above that when the human being engages in the activity of disconnecting the LV cable, he is still immersed in the zone of the live HV electromagnetic field even if the LV supply has been de-energized.

However, we are only considering a situation where only HV is energizedand LV is disconnected. This could happen when

\begin{tabular}{|c|c|c|c|c|c|c|c|c|c|}
\hline \multirow{2}{*}{ Designation } & \multirow{2}{*}{$\begin{array}{l}\text { Impedance } \\
\text { values }(\Omega)\end{array}$} & \multicolumn{3}{|c|}{ HV Self Impedances $\left(Z_{1 p}{ }^{\star} Z_{10} /\left(Z_{1 P}+Z_{10}\right)\right)$} & \multicolumn{3}{|c|}{ LV Self/mutual Impedances $\left(Z_{i 0}{ }^{*} Z_{i j} /\left(Z_{i 0}+Z_{i n}\right)\right)$} & \multicolumn{2}{|c|}{ Equivalent LV Impedances in Parallel } \\
\hline & & $\mathrm{Z}_{\mathrm{B}}$ & $Z_{S}$ & $\mathrm{Z}_{\mathrm{T}}$ & $Z_{r}$ & \begin{tabular}{|c|}
$Z_{s}$ \\
\end{tabular} & & $s=Z_{r}^{*} Z_{s} /\left(Z_{r}+Z\right.$ & $Z_{E(\text { ea) }}=Z_{\text {rs }}{ }^{*} Z_{t} /\left(Z_{\text {si }}+Z_{t}\right)$ \\
\hline$Z_{\mathrm{Br}}$ & $46,073,871.23$ & $1.017 \mathrm{E}+08$ & $1.017 \mathrm{E}+08$ & $101,745,414.08$ & $8.080 \mathrm{E}+07$ & $51,190,820.55$ & $52,728,866.63$ & $31,336,752.68$ & $19,655,496.10$ \\
\hline$Z_{\gamma_{r}}$ & $46,297,634.88$ & & & & & & & & \\
\hline$Z_{B r}$ & $45,141,187.20$ & \multicolumn{3}{|c|}{ HV Total Impedances $(\Omega)$} & \multicolumn{5}{|c|}{ Victim's Average Impedance Values $(\Omega)$} \\
\hline$\frac{Z_{r}}{Z_{n}}$ & $87,446,689.23$ & $Z_{R}+Z_{R r}$ & $L_{S}+L_{S r}$ & $Z_{T}+L_{T r}$ & \multirow{2}{*}{\multicolumn{2}{|c|}{ Capacitance $\mathrm{C}_{\mathrm{H}}\left(\times 10^{-9} \mathrm{~F}\right)$}} & \multicolumn{3}{|c|}{ Calculated Impedance $(\Omega)$} \\
\hline$Z_{\mathrm{w}}$ & $105,457,733.26$ & $1.478 \mathrm{E}+08$ & $1.480 \mathrm{E}+08$ & $146,886,601.29$ & & & Capacitive & Resistive & Average \\
\hline$Z_{B 0}$ & $203,490,828.17$ & & & & Isolated on Pole & 180 & $17,683.88$ & $\mathrm{NIL}$ & $17,683.88$ \\
\hline$\frac{Z_{Y 0}}{Z_{Y 0}}$ & $203,490,828.17$ & & & & Hands on LV & 125 & $25,464.79$ & 250 & 247.57 \\
\hline$Z_{B_{0}}$ & $203,490,828.17$ & & & & Hands on LV, & & & & \\
\hline$Z_{B P}$ & $203,490,828.17$ & & & & Feet on Neutral & 125 & $25,464.79$ & 600 & 586.19 \\
\hline$Z_{Y p}$ & $203,490,828.17$ & & & & \multicolumn{5}{|c|}{ HV/Victim/LV Impedance $(\Omega)$} \\
\hline$Z_{B P}$ & $203,490,828.17$ & & & & \multirow{2}{*}{\multicolumn{2}{|c|}{$\begin{array}{l}\text { Impedance with Victim Direct on } \\
\text { LV Line Terminals only }(\Omega)\end{array}$}} & \multirow{2}{*}{\multicolumn{2}{|c|}{$\begin{array}{l}\text { Impedance with Victim Direct on } \\
\text { Transformer LV Terminals }(\Omega)\end{array}$}} & \\
\hline$\frac{Z_{10}}{Z_{0}}$ & $134,004,562.63$ & & & & & & & & \\
\hline$Z_{v 0}$ & $123,468,777.28$ & & & & Without Transf. & Feet on Transf. w dd & With both Hands & Across Tranf. Wdg. & \\
\hline$Z_{b 0}$ & $105,457,733.26$ & & & & $19,673,179.98$ & $17,683.88$ & 247.57 & $1.089 \mathrm{E}-05$ & \\
\hline
\end{tabular}
the victim climbs the pole during the usual power failure from the HV(automatically knocking off the LV side of the substation) and there is a sudden power restoration, which always happens in $90 \%$ of this type of scenario.

Our impedance network analysis will first consider the situation of a normal operation and then the case of the man in question climbing the pole for his activities. We shall compare the results of the two conditions and its effect on the victim.

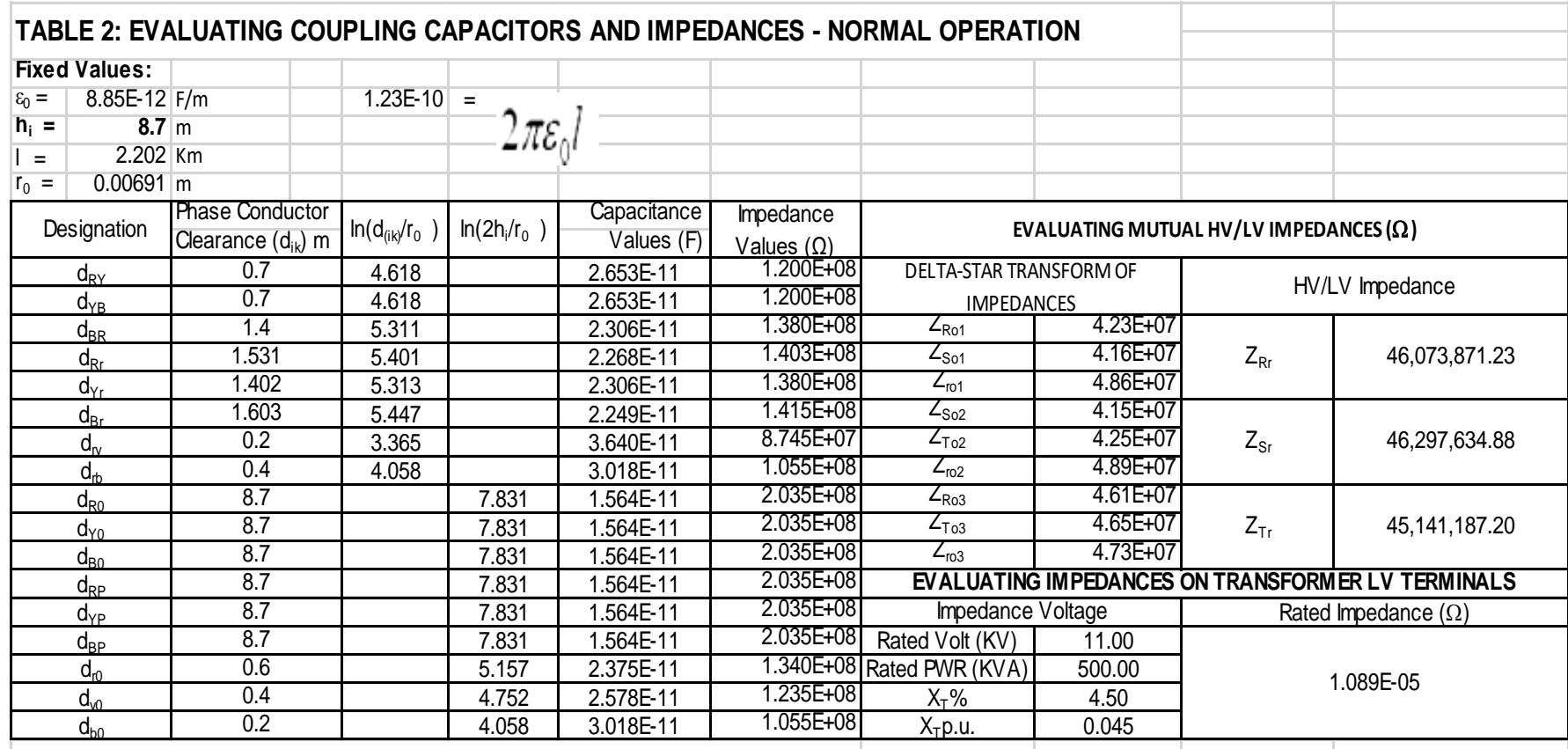

TABLE 3: IMPEDANCE MATRIX - NORMAL CLEARANCE 
From figure 12(a)

$$
\left.\begin{array}{lll}
\mathbf{Z}_{\mathrm{T}} & = & \mathbf{Z}_{\mathrm{TP}} * \mathbf{Z}_{\mathrm{T} 0} /\left(\mathbf{Z}_{\mathrm{TP}}+\mathbf{Z}_{\mathrm{T} 0}\right) \\
\mathbf{Z}_{\mathrm{S}} \quad= & \mathbf{Z}_{\mathrm{SP}} * \mathbf{Z}_{\mathrm{S} 0} /\left(\mathbf{Z}_{\mathrm{SP}}+\mathbf{Z}_{\mathrm{S} 0}\right) \\
\mathbf{Z}_{\mathrm{R}} \quad= & \mathbf{Z}_{\mathrm{RP}} * \mathbf{Z}_{\mathrm{R} 0} /\left(\mathbf{Z}_{\mathrm{RP}}+\mathbf{Z}_{\mathrm{R} 0}\right)
\end{array}\right\}
$$

Since our consideration is purely electric field effect,HumanBody capacitance,the physical property of the human body that has it act as a capacitor like any other electrically-conductive object. The human body capacitance to a far ground is $100-200 \mathrm{pF}$. We shall assume $180 \mathrm{pF}$ in this case. This is now inserted between the $\mathrm{HV}$ and $\mathrm{LV}$ terminals in figure $12 \mathrm{~b}$.

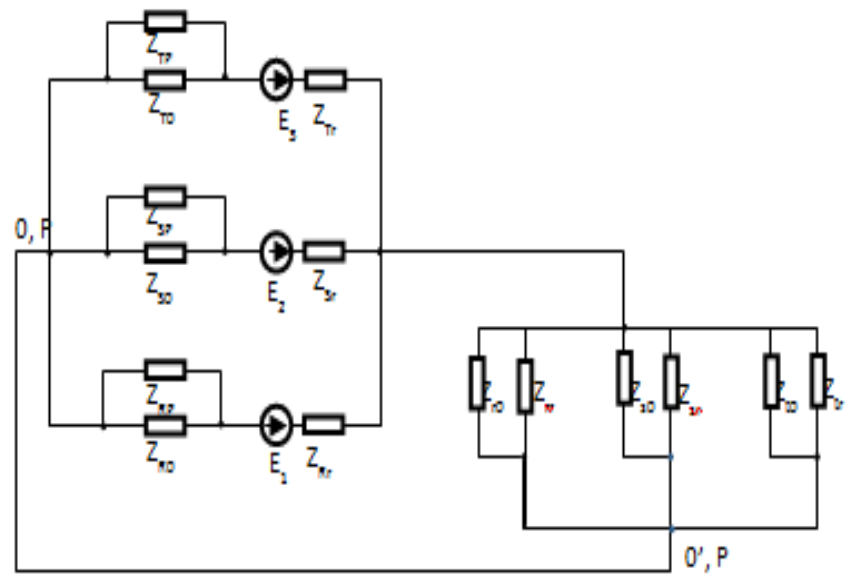

Fig 12a: Impedances of active HV/LV Network

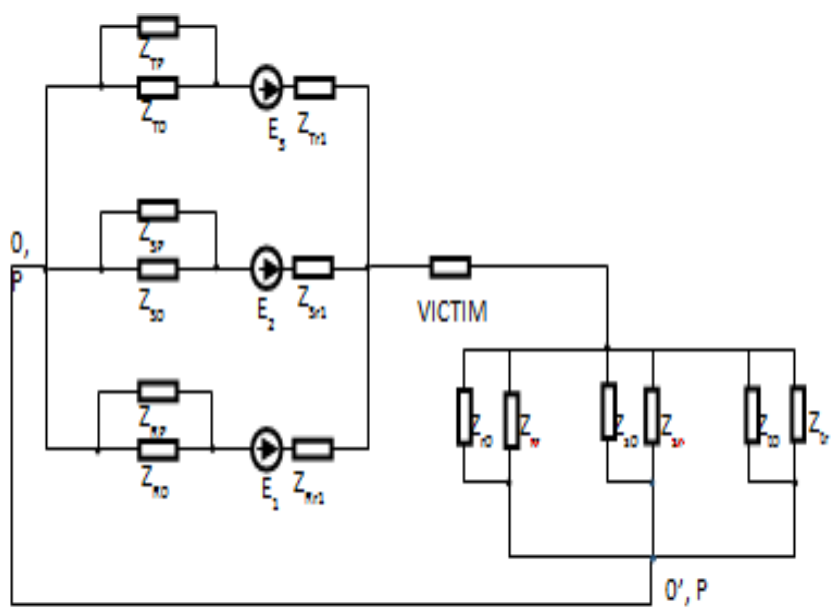

Fig 12b: Impedance Network during the Electrocution.

In the first instance we are assuming live conductors in both cases (HV and LV).The impedances of the active/passive Low Voltage Network now form the return path through ground in series with the victim's body resistance as shown in figure $12 \mathrm{~b}$ above.
From figure $12(\mathrm{a})$, after combination of $\mathrm{Z}_{\mathrm{iO}}$ and $\mathrm{Z}_{\mathrm{iP}}$ in parallel, i.e $\mathrm{Z}_{\mathrm{I}}=\left(\mathrm{Z}_{\mathrm{iO}} * \mathrm{Z}_{\mathrm{iP}}\right) /\left(\mathrm{Z}_{\mathrm{iO}}+\mathrm{Z}_{\mathrm{iP}}\right)$ for $\mathrm{I}=\mathrm{R}, \mathrm{S}, \mathrm{T}$

$$
\begin{aligned}
& \left.\begin{array}{ll}
E_{1}-E_{2} & =\left(Z_{R}+Z_{\mathrm{Rr}}\right) \cdot \mathbf{I}_{1}-\left(Z_{\mathrm{S}}+Z_{\mathrm{Sr}}\right) \cdot \mathbf{I}_{2} \\
\mathbf{E}_{2}-\mathbf{E}_{3} & =\left(Z_{\mathrm{S}} Z_{\mathrm{Sr}}\right) \cdot \mathbf{I}_{2}-\left(Z_{\mathrm{T}^{+}} Z_{\mathrm{Tr}}\right) \cdot \mathbf{I}_{3} \\
\mathbf{E}_{3} & =\left(Z_{\mathrm{T}}+Z_{\mathrm{Tr}}\right) \cdot \mathbf{I}_{3}+\mathbf{Z}_{\mathrm{E}(\mathrm{eq})} \mathbf{I} \\
\mathbf{0} & =\quad \mathbf{I}_{1}+\mathbf{I}_{2}+\mathbf{I}_{3}-\mathbf{I}
\end{array}\right\}
\end{aligned}
$$

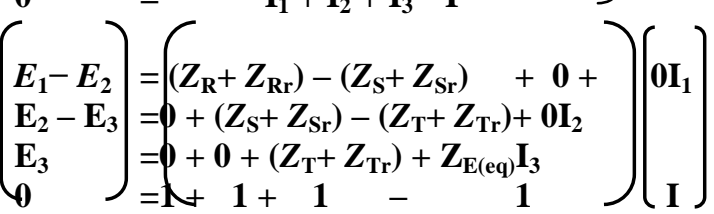

From figure $12 \mathrm{~b}$

$\left(\begin{array}{l}E_{1}-E_{2} \\ \mathbf{E}_{2}-\mathbf{E}_{3} \\ \mathbf{E}_{3} \\ 0\end{array}\right)=\left(\begin{array}{cc}\left.Z_{\mathrm{R}}+Z_{\mathrm{Rr} 1}\right)-\left(Z_{\mathrm{S}}+Z_{\mathrm{Sr} 1}\right)+\mathbf{0}+\mathbf{0} & \mathbf{I}_{1} \\ 0+\left(Z_{\mathrm{S}}+Z_{\mathrm{Sr} 1}\right)-\left(Z_{\mathrm{T}}+Z_{\mathrm{Tr} 1}\right)+0 \mathbf{I}_{2} \\ +0+\left(Z_{\mathrm{T}}+Z_{\mathrm{Tr} 1}\right)+\left(\mathbf{Z}_{\mathrm{E}}+\mathbf{Z}_{\mathrm{E} 1(\mathrm{eq})}\right) \mathbf{I}_{3} \\ 1+1+1 & \mathbf{I}\end{array}\right)\left(\begin{array}{l}1 \\ 1+1\end{array}\right)$

The evaluated results of the transformed Impedance Network are follows:

\section{IMPEDANCE MATRIX - NORMAL OPERATION

$$
\begin{array}{ll}
\mathrm{Z}_{\mathrm{R}}+\mathrm{Z}_{\mathrm{Rr}} & 147,819,285.31 \\
\mathrm{Z}_{\mathrm{S}}+\mathrm{Z}_{\mathrm{Sr}} & 148,043,048.96 \\
\mathrm{Z}_{\mathrm{T}}+\mathrm{Z}_{\mathrm{Tr}} & 146,886,601.29
\end{array}
$$

IMPEDANCE MATRIX - ALLOWABLE SAFE LIMIT

$$
\begin{aligned}
& \mathrm{Z}_{\mathrm{R}}+\mathrm{Z}_{\mathrm{Rr}} \\
& \mathrm{Z}_{\mathrm{S}}+\mathrm{Z}_{\mathrm{Sr}} \\
& \mathrm{Z}_{\mathrm{T}}+\mathrm{Z}_{\mathrm{Tr}} \\
& \mathrm{Z}_{\text {VICTIM }}
\end{aligned}
$$$$
17,683.88
$$

The Matrix equation is of the form:

$$
A * X=B
$$

It must be borne in mind that that the 'let-go' current for an average man as confirmed by NIOSH studies is $16 \mathrm{~mA} \mathrm{[19].}$ Consensus universal studies peg it at $10-40 \mathrm{~mA}$. Therefore, we will simulate condition of average let-go current to determine minimum value of induced voltage in this situation.

From the same reference, ventricular fibrillation threshold is $100 \mathrm{~mA}$; and so we assume theminimum electrocution current $100 \mathrm{~mA}$. We shall use this values to evaluate practical results and establish the implications of the above impedance values.

Assuming a condition of no-load, we will evaluate Computer Matrix Equation for table3 using:

1. The impedance values on the table above 
2. Various positions of the victim at allowable safe clearance limit

3. Minimum threshold of Electrocution Current.

The results of the evaluationsare given as follows with the circulating current distributable as shown:

Table 4: Solution to Matrix A*X=B for Allowable Safe Clearance Limit condition

Input Matrix A:

$143542809.230-144205490.720 \quad 0.000 \quad 0.000$

$0.000144205490 .720 \quad 0.000 \quad 0.000$

$0.000 \quad 0.000 \quad 141266047.190 \quad 19655496.100$

$1.0001 .0001 .000-1.000$

\begin{tabular}{|l|l|}
\multicolumn{1}{|c}{ Input Matrix B: } & \multicolumn{1}{c|}{ Solution $A * \mathbf{X}=\mathbf{B}$} \\
\hline 11000.0000 & $0.000153=I_{1}$ \\
11000.0000 & $0.000076=I_{2}$ \\
6350.0000 & $0.000011=I_{3}$ \\
0.0000 & $0.000241=I$ \\
\hline
\end{tabular}

It is obvious from the above results the there is virtually no enough current flow under normal operating condition to result to significant induced voltage on the LV terminals. We therefore decided to investigate effect with the victim between HV terminals and LV Lines as shown on table 5 below.

Table 5: Solution to Matrix $A * X=B$ for Victim between $\mathrm{HV}$ and LV line terminals only

Input Matrix A:

$143542809.230-144205490.720 \quad 0.000 \quad 0.000$

$0.000 \quad 144205490.720-141266047.190 \quad 0.000$

$0.000 \quad 0.000 \quad 141266047.190 \quad 19673179.880$

$1.0000001 .0000001 .000000-1.000000$

\begin{tabular}{|l|}
\multicolumn{1}{|c|}{ Input Matrix A: } \\
\hline 11000.0000 \\
11000.0000 \\
6350.0000 \\
0.0000 \\
\hline
\end{tabular}

Solution $\mathbf{A} * \mathbf{X}=\mathbf{B}$
\begin{tabular}{|l|}
$0.000162=I_{1}$ \\
$0.000085=I_{2}$ \\
$0.000009=I_{3}$ \\
$0.000257=I$
\end{tabular}

For the Victim in Direct contact with the transformer LV terminals, the results are as follows:

Table 6: Solution to Matrix $A * X=B$ for Victim between $\mathrm{HV}$ and transformer LV terminals

Input Matrix A:

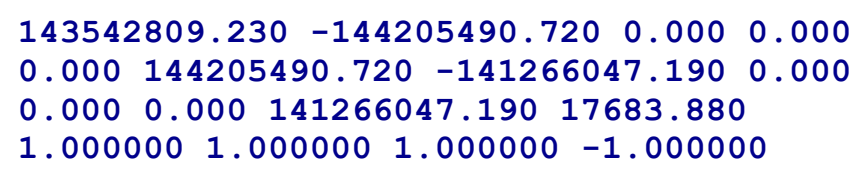

\begin{tabular}{|l|}
\multicolumn{1}{c|}{ Input Matrix A: } \\
\hline 11000.0000 \\
11000.0000 \\
6350.0000 \\
0.0000
\end{tabular}

Solution $\mathbf{A} * \mathbf{X}=\mathbf{B}$
\begin{tabular}{|l}
$0.000197=I_{1}$ \\
$0.000120=I_{2}$ \\
$0.000045=I_{3}$ \\
$0.000363=I$ \\
\hline
\end{tabular}

Four obvious positions of the victim used for this analysis as in table 3 are as follows:

a) In contact with LV lines isolated from transformer.

b) Standing in Electric Field feet on transf. LV terminals

c) With both hands direct on transformer LV terminals

d) Both hands on LV windings, feet on neutral/Ground.

It was obvious from our analysis as in the table6above that whatever the position, the current cannot be more than $0.363 \mathrm{~mA}$ which is below the 'let-go' current. This current is contributedfrom the phases as follows:

$\begin{array}{lll}\text { Red } & = & 54 \% \text { of Circulating Current; } \\ \text { Yellow } & = & 33 \% \text { of Circulating Current } \\ \text { Blue } & = & 13 \% \text { of Circulating Current }\end{array}$

This forms our basis for allocating simulation current for further evaluation.

The above evaluation has assumed the phase-neutral Capacitive impedances for the Lines on each phase as follows:

$\begin{array}{llc}\mathbf{Z}_{\mathrm{A}} & = & 101,745,414.08 \Omega \\ \mathbf{Z}_{\mathrm{B}} & = & 101,745,414.08 \Omega \\ \mathbf{Z}_{\mathrm{C}} & = & 101,745,414.08 \Omega \\ \mathbf{Z}_{\mathrm{LV}(\text { eq) }} & = & 19,655,496.10 \Omega\end{array}$

The impedances network with LV passive (i.e. deenergised)is illustrated in the equivalent diagram of figure 13 below.

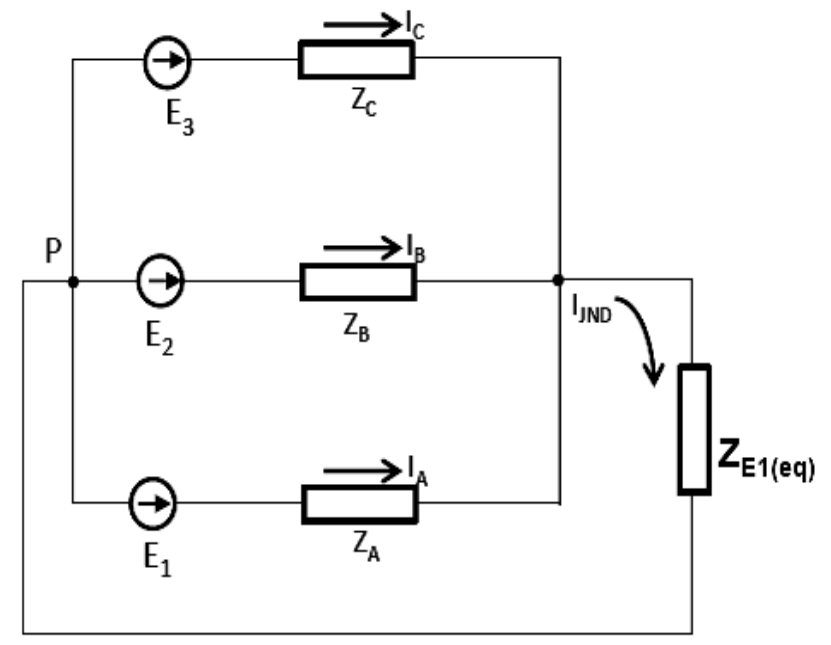

Fig 13: Network Equivalent Impedances

The scenario where the standard clearance (impedances) are maintained between the $\mathrm{HV}$ and $\mathrm{LV}$ phases and the man 
climbs up the pole was evaluated. It shows that even if the victim's impedance was connected across transformer LV windings (about $109 \mathrm{~m} \Omega$ from table 3 ), the total circuit current cannot be more than $0.363 \mathrm{~mA}$ as indicated earlier.

We will now assume a minimum electrocution current of $100 \mathrm{~mA}$ and establish the impedances that can cause this current to circulate as shown in the matrix table 7 below. This current is distributable on the phases as earlier evaluated:

Red $=54 \%$ of Circulating Current $=54 \mathrm{~mA}$

Yellow $=33 \%$ of Circulating Current $=33 \mathrm{~mA}$

Blue $=13 \%$ of Circulating Current $=13 \mathrm{~mA}$

Table 7: Results with Electrocution Current of 100mA

Input Matrix A

$0.054-0.033 \quad 0.000 \quad 0.000$

$0.000 \quad 0.033-0.013 \quad 0.000$

$0.000 \quad 0.000 \quad 0.0130 .100$

$1.0001 .0001 .000-0.100$

Solution $\mathbf{A} * \mathbf{X}=\mathbf{B}$

$300106.380=Z_{A}$
$157749.834=Z_{B}$
$-445711.959=Z_{C}$
$121442.555=Z_{E}$

$\mathrm{Z}_{\mathrm{R}}+\mathrm{Z}_{\mathrm{Rr}}=$

$\mathrm{Z}_{\mathrm{A}} \quad=$

$300,106.38 \Omega$

$\mathrm{Z}_{\mathrm{S}}+\mathrm{Z}_{\mathrm{Sr}}=$

$\mathrm{Z}_{\mathrm{B}} \quad=$

$157,749.83 \Omega$

$\mathrm{Z}_{\mathrm{T}}+\mathrm{Z}_{\mathrm{Tr}}=$

$\mathrm{Z}_{\mathrm{C}} \quad=$

$-445,711.96 \Omega$

$\mathrm{Z}_{\mathrm{E} 1(\mathrm{eq})}=$

$\mathrm{Z}_{4} \quad=$

$121,442.56 \Omega$

Therefore, Induced voltage during electrocution is given by:

$$
\begin{aligned}
\mathrm{V}_{\mathrm{IND}}=\quad \mathrm{I}_{\mathrm{E}} \mathrm{Z}_{\mathrm{E}} & =0.100 * 121,442.56 \\
& =12,144.256 \mathrm{Vol} \\
& \mathbf{1 2 . 1 4 4 K V}
\end{aligned}
$$

Our equivalent clearance evaluation shows that the victim could have been within the following clearance ranges for the given conditions:

\begin{tabular}{|c|c|c|c|c|c|c|}
\hline \multirow{2}{*}{$\begin{array}{l}\text { Phas } \\
\text { e } \\
\text { Impe } \\
\text { danc } \\
\text { es }\end{array}$} & \multirow{2}{*}{$\begin{array}{l}\text { Impedan } \\
\text { ce } \\
\text { Values } \\
(\mathrm{M} \Omega)\end{array}$} & \multicolumn{2}{|c|}{$\begin{array}{l}\text { Coordinate } \\
\text { Imp.(M } \Omega)\end{array}$} & \multicolumn{2}{|c|}{$\begin{array}{l}\text { Capacitances } \\
(\mu \mathrm{F})\end{array}$} & $\begin{array}{l}\text { Clear } \\
\text { ance } \\
(\mathrm{m}) \\
\end{array}$ \\
\hline & & $\mathrm{Z}_{\mathrm{Y}}$ & $\mathrm{Z}_{\mathrm{X}}$ & $\mathrm{C}_{\mathrm{Y}}$ & $\mathrm{C}_{\mathrm{X}}$ & $\begin{array}{l}\mathrm{d}_{\mathrm{X}}= \\
\mathrm{d}_{(\mathrm{ik})}\end{array}$ \\
\hline \multicolumn{7}{|c|}{ VALUES FOR NORMAL OPERATION } \\
\hline $\mathrm{Z}_{\mathrm{A}}$ & 242.08 & $\begin{array}{l}101 . \\
75\end{array}$ & $\begin{array}{l}140 . \\
33\end{array}$ & $\begin{array}{l}0.31 \\
3 \\
\end{array}$ & $\begin{array}{l}0.22 \\
7\end{array}$ & 1.531 \\
\hline $\mathrm{Z}_{\mathrm{B}}$ & 239.79 & $\begin{array}{l}101 . \\
75\end{array}$ & $\begin{array}{l}138 . \\
05\end{array}$ & $\begin{array}{l}0.31 \\
3 \\
\end{array}$ & $\begin{array}{l}0.23 \\
1 \\
\end{array}$ & 1.402 \\
\hline $\mathrm{Z}_{\mathrm{C}}$ & 243.27 & $\begin{array}{l}101 . \\
75\end{array}$ & $\begin{array}{l}141 . \\
53\end{array}$ & $\begin{array}{l}0.31 \\
3 \\
\end{array}$ & $\begin{array}{l}0.22 \\
5 \\
\end{array}$ & 1.603 \\
\hline
\end{tabular}

Table 8: Evaluated Clearances for various Conditions

\begin{tabular}{|c|c|c|c|c|c|c|}
\hline \multicolumn{7}{|c|}{ VALUES FOR ALLOWABLE SAFE LIMIT } \\
\hline $\mathrm{Z}_{\mathrm{A}}$ & 227.18 & $\begin{array}{l}101 . \\
75\end{array}$ & $\begin{array}{l}125 . \\
38\end{array}$ & $\begin{array}{l}0.31 \\
3\end{array}$ & $\begin{array}{l}0.25 \\
4\end{array}$ & 0.863 \\
\hline $\mathrm{Z}_{\mathrm{B}}$ & 217.95 & $\begin{array}{l}101 . \\
75\end{array}$ & $\begin{array}{l}116 . \\
21\end{array}$ & $\begin{array}{l}0.31 \\
3\end{array}$ & $\begin{array}{l}0.27 \\
4\end{array}$ & 0.605 \\
\hline $\mathrm{Z}_{\mathrm{C}}$ & 230.59 & $\begin{array}{ll}101 . \\
75\end{array}$ & $\begin{array}{l}128 . \\
85\end{array}$ & $\begin{array}{l}0.31 \\
3\end{array}$ & $\begin{array}{l}0.24 \\
7\end{array}$ & 0.984 \\
\hline \multicolumn{7}{|c|}{$\begin{array}{llll}\text { VALUES } & \text { FOR } & \text { ELECTROCUTION } & \text { CURRENT } \\
(100 \mathrm{~mA}) & \end{array}$} \\
\hline $\mathrm{Z}_{\mathrm{A}}$ & 0.300 & $\begin{array}{l}0.13 \\
4\end{array}$ & $\begin{array}{l}0.16 \\
5\end{array}$ & $\begin{array}{l}0.00 \\
24\end{array}$ & $\begin{array}{l}0.00 \\
19\end{array}$ & $\begin{array}{l}0.007 \\
0\end{array}$ \\
\hline $\mathrm{Z}_{\mathrm{B}}$ & 0.157 & $\begin{array}{l}0.07 \\
4\end{array}$ & $\begin{array}{l}0.08 \\
4\end{array}$ & $\begin{array}{l}0.04 \\
3\end{array}$ & $\begin{array}{l}0.00 \\
38\end{array}$ & $\begin{array}{l}0.006 \\
9\end{array}$ \\
\hline $\mathrm{Z}_{\mathrm{C}}$ & 0.445 & $\begin{array}{l}0.19 \\
6\end{array}$ & $\begin{array}{l}0.24 \\
9\end{array}$ & $\begin{array}{l}0.00 \\
16\end{array}$ & $\begin{array}{l}0.00 \\
13\end{array}$ & $\begin{array}{l}0.007 \\
0\end{array}$ \\
\hline
\end{tabular}

\subsubsection{Influence of Human Dielectric Constant}

Calculation of the electric field strength is made according to image and superposition theorems. The permittivity of vacuum, $\varepsilon_{0}=8.85 \cdot 10^{-12} \mathrm{~F} / \mathrm{m}$, is assumed everywhere and the earth is considered as a perfect conductor. Lateral distribution of the electric field strength depends on the phase arrangement in power lines. Underneath the power line, the same phase arrangement produces the highest electric field strength.

Electric field is force per charge and potential is potential energy per charge. So electric field and potential are linked in the same way that the concepts of force and potential energy are linked.

If electric field is defined as the electric force per unit charge andthe direction of the field is taken to be the direction of the force it would exert on $\rightarrow$ a positive test charge, then;

$$
\begin{aligned}
& \mathrm{E} \quad=\quad \mathbf{F} / \mathbf{q}=\mathrm{kQ} / \mathbf{r}^{2} \\
& \mathrm{~F} \quad=\quad q E
\end{aligned}
$$

A charged particle's potential energy $U$ at the point is given by the simple relation:

$$
U \quad=\quad q V
$$

It is established that change in potential energy is defined as the negative of the work done by a conservative force,

$$
\Delta U=-\Delta W
$$

Since the field is uniform the force doesn't change and the work done by the electrostatic force is just the product of the 
displacement and force's component in the direction of the displacement;

$$
W \quad=\quad-q E l
$$

Since the change in PE is equal to minus the work done by the electrostatic force

$$
U_{\mathrm{B}}-U_{\mathrm{A}}=q E l
$$

Potential difference between points $\mathrm{A}$ and $\mathrm{B}$ is the change in Potential Energy per charge, i.e.

$$
V_{\mathrm{B}}-V_{\mathrm{A}}=\quad E l
$$

Therefore, Minimum Electric Field value in this electrocution can be evaluated using this relation together with the result of induced voltage calculation above.

Now, from the relationship;

$$
X_{\mathrm{C}}=1 /(2 \pi \mathrm{fC})
$$

It is obvious that reduction in impedance means increase in capacitance, therefore, an increase in relative permittivity.

An Electric Field perpendicular to two poles of the enclosed air dielectric between the HV/LV terminals can be visualized as indicated in figure 14 below causes charges of magnitude Pper unit area on the terminals. The field strength $\mathbf{E}$ inside the dielectric is then given by;

$$
\mathbf{E}=\quad \mathbf{E}_{\mathbf{O}}-\mathbf{P} / \varepsilon_{0}
$$

Where, $\varepsilon_{0}=\mathbf{8 . 8 5 4 \times 1 0 ^ { - 1 2 }} \mathbf{F m}^{-1}$ (the permittivity of vacuum).

It will have a Capacitance $\mathbf{C}$ between the two terminals each of surface area $\mathbf{A}$, separated by a distance $\mathbf{d}$ in vacuo and connected to a voltage source of strength $\mathbf{V}$ (figure 15a). Current flows from the voltage source until there is a charge of magnitude $\mathbf{Q}$ on each terminal, so that;

$$
\mathbf{Q}=\mathbf{C V}
$$

The Capacitance of the Capacitor is given by;

$$
\mathrm{C}=\varepsilon_{\mathbf{O}} \mathrm{A} / \mathrm{d}
$$

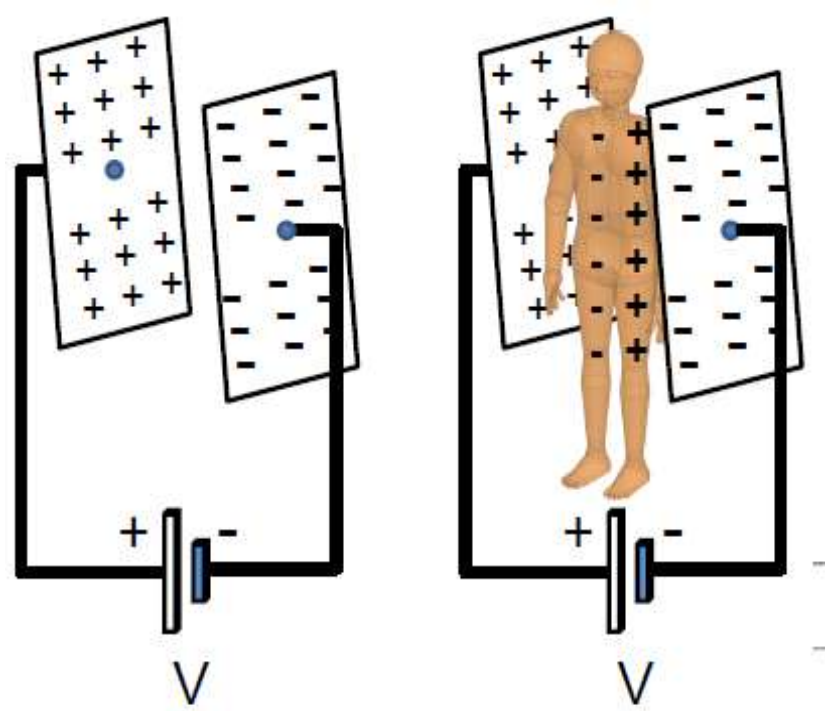

Fig 14: Capacitor (a) without and (b) with human dielectric

When a new dielectric material is placed in the gap, it becomes polarized due to the field and charges appear on the surface of the material (the victim in this case) as shown in figure $14 \mathrm{~b}$.

The voltage difference of the terminals will remain constant because they are connected to the source so that current flows from source to build up an extra charge on each terminal. This extra charge is equal to the final induced charge on the dielectric surface and of opposite sign. The total charge is then given by;

$$
\begin{array}{lll}
\mathbf{Q}^{\prime} & = & \mathbf{C}^{\prime} \mathbf{V} \\
\mathbf{C}^{\prime} & = & \mathbf{E A} / \mathbf{d}
\end{array}
$$

Where, $\boldsymbol{\varepsilon}$ is the permittivity of the human body. Typical values of the Dielectric Constants of various parts of human body are shown on table 9 below.

When the 'humandielectric' is placed between the plates of a capacitor it increases the capacitance. The capacitance increases by the factor $\kappa$ when the dielectric completely fills the region between the plates ( $\boldsymbol{\kappa}$ is the dielectric constant of the material).

It can be shown from equations (9) and (12) that;

$$
\mathbf{Q}^{\prime} \quad=\quad \mathbf{Q}+\mathbf{Q}_{0}=\quad \mathbf{Q}+\mathbf{P A}
$$

And from (7) and (10) above;

$$
\begin{aligned}
\varepsilon A V / d & =\varepsilon_{0} A V / d+P A \\
\therefore P & =\quad\left(\varepsilon-\varepsilon_{0}\right) V / d \\
= & \left(\varepsilon-\varepsilon_{0}\right) \mathrm{E}
\end{aligned}
$$


Table 9: Complex Dielectric Constants for Various Human Structures

\begin{tabular}{|c|c|c|}
\hline $\begin{array}{c}\text { Anatomical } \\
\text { Structure }\end{array}$ & Epsilon ( $\boldsymbol{\varepsilon}$ & Sigma ( $\boldsymbol{\sigma})$ \\
\hline Bone & 12.4 & 0.2 \\
\hline Fat & 4.72 & 0.05 \\
\hline Muscle & 60 & 1.32 \\
\hline Skin & 39.9 & 0.72 \\
\hline Lung & 20.5 & 0.42 \\
\hline Heart & 57.48 & 1.22 \\
\hline Trachea & 55.9 & 1.12 \\
\hline Cerebra Spinal Fluid & 68.1 & 2.45 \\
\hline Esophagus & 71.1 & 1.35 \\
\hline
\end{tabular}

Where $\mathbf{E}(=\mathbf{V} / \mathbf{d})$ is the electric field.

The ratio of the two capacitances, $\mathbf{C}$ and $\mathbf{C}^{\prime}$ is given by;

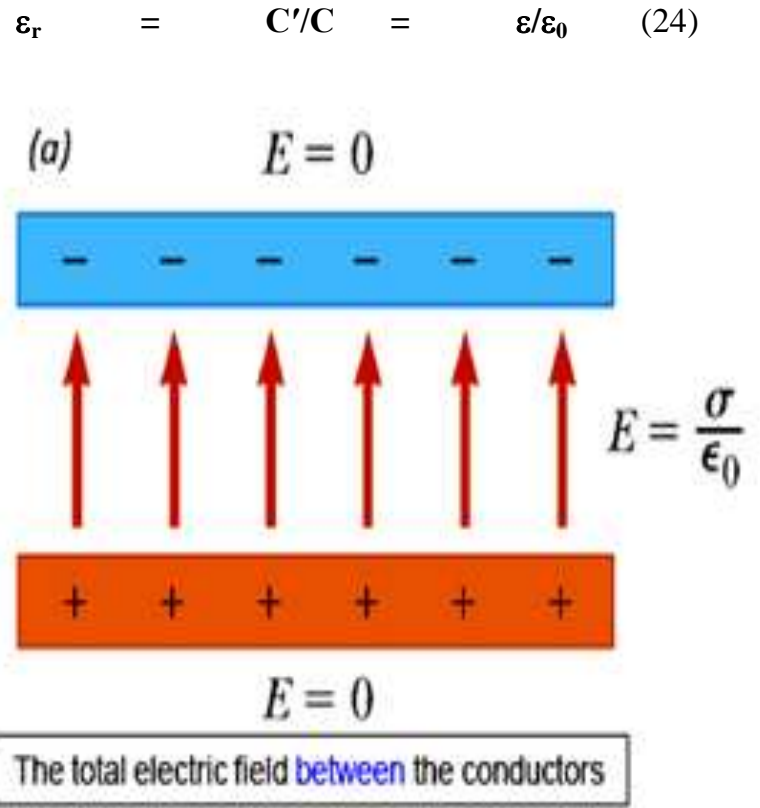

Where $\varepsilon_{\mathrm{r}}$ is the relative permittivity or dielectric constant given on table 9 above.

In electromagnetism, permittivity or absolute permittivity is the measure of resistance that is encountered when forming an electric field in a medium. In other words, permittivity is a measure of how an electric field affects, and is affected by, a dielectric medium. The permittivity of a medium describes how much electric field (more correctly, flux) is 'generated' per unit charge in that medium. More electric flux exists in a medium with a low permittivity (per unit charge) because of polarization effects.

The case under consideration can be adequately evaluated as illustrated in figure 15.

(b)

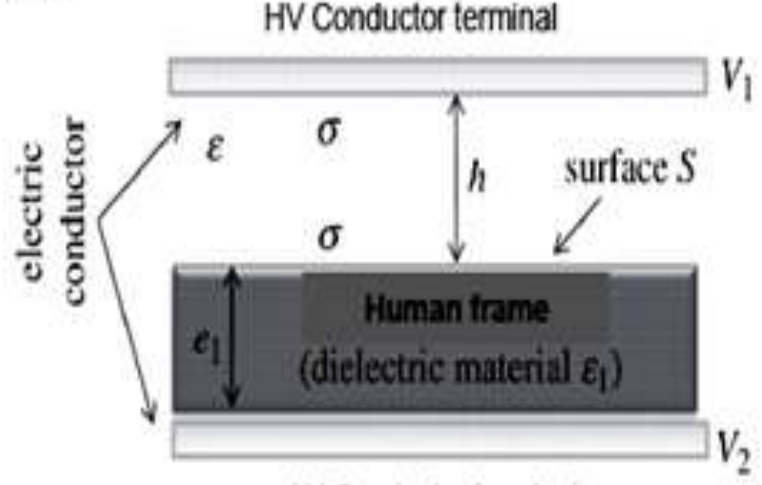

LV Conductor terminal

Electric field with Human Dielectric between the conductors

Fig 15: Illustrating capacitive effect with human dielectric

It should be noted that the man's physical contact is with the LV conductor terminal. According to C. PaillerMattei et al, if we neglect the boundary effect, the electric charge, $Q$, on the skin surface can be estimated using the example of capacitor with dielectric material inside the model [3].

The electric field intensity between the HV terminal and the dielectric material, $E_{0}$, and inside the dielectric material, $E_{l}$, are, respectively

$$
E_{0}=\frac{\sigma}{\varepsilon_{0}}
$$

And,

$$
E_{1}=\frac{\sigma}{\varepsilon_{1}}
$$

Where, $\sigma$ is the surface charge density on the HV terminal. If the $\mathrm{HV}$ terminal is above the victim at a distance $h$, and the thickness, $e_{1}$, of the dielectric material inside the imaginary capacitor, symbolizes the human body-mass, the electrical potential difference, $V$, between the $\mathrm{LV}$ metallic support for the forearm and the HV terminal is given as [3]; 


$$
V=V_{1}-V_{2}=E_{0} h+E_{1} e_{1},
$$

Therefore (from (18) and (19));

$$
V=\sigma\left(\frac{h}{\varepsilon_{0}}+\frac{e_{1}}{\varepsilon_{1}}\right)
$$

If $S$ is the surface area of the victim in contact with the electric field, the surface charge density, $\sigma$, is defined as $\sigma=$ $Q / S$; therefore, the potential difference can be written as a function of electric charge, $Q$, as

$$
V=\frac{Q}{S}\left(\frac{h}{\varepsilon_{0}}+\frac{e_{1}}{\varepsilon_{1}}\right)
$$

As a consequence the electric charge, $Q$, on the human skin surface is

$$
Q=\frac{\varepsilon_{0} V S}{\left(h+\left(e_{1} / \varepsilon_{r(\text { skin })}\right)\right)},
$$

Where, $\varepsilon_{r(\text { skin })}$ is the skin relative permittivity given by $\varepsilon_{1}=\varepsilon_{0} \varepsilon_{r(\text { skin })}$.

The electrical properties of many biological materials are known to exhibit frequency dispersions. In the human skin, the impedance measured at various frequencies closely describes a circular locus of the Cole-Cole type in the complex impedance plane.

With the results obtained in the analysis and table 9, actual values of parameters can be evaluated.

\subsubsection{Interpretation \& Conclusion}

Going by the various technical evaluations above, it can be safely concluded that:

i. The victim actually acted as a human dielectric material inserted between the $\mathrm{HV}$ and $\mathrm{LV}$ terminals and not as a mere parallel impedance with LV terminalas assumed. The body capacitanceof a human being would be low when standing on top of a pole isolated from ground. The capacitive reactance becomes more significant than the body resistance. Therefore, the true picture of the illustration of figures $7(\mathrm{a}),(\mathrm{b})$ is correctly reproduced in figure 16 below.

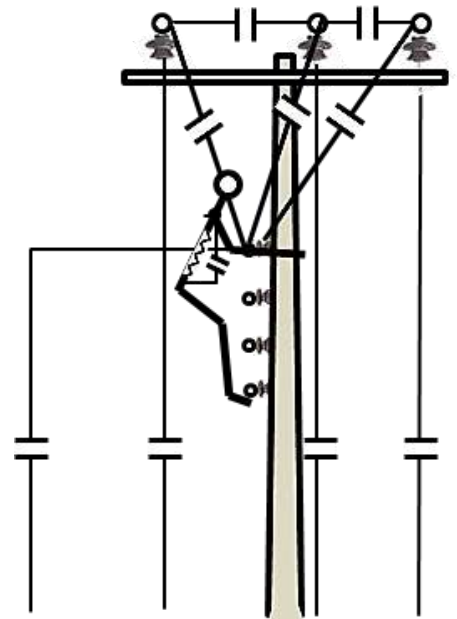

Fig 16: The Human Resistive Network between HV/LV

Now from (29),

$$
Q=\frac{\varepsilon_{0} V S}{\left(h+\left(e_{1} / \varepsilon_{r(\text { skin })}\right)\right)},
$$

And

$$
\begin{array}{llll}
\mathbf{Z}_{\mathrm{C}} & = & \mathbf{1} /(\mathbf{2 \pi f \mathrm { C } )} & \text { from (8) } \\
\mathbf{Q} & = & \mathbf{C V} & \text { from (10) }
\end{array}
$$

The results of the impedance and equivalent clearancecalculationsat power frequency of $50 \mathrm{~Hz}$, have already been obtained. It is obvious that, all things being equal, for this electrocution to rely on capacitive reactance alone, the victim has to be pretty close to the HV terminals.

However, we will take a look at other related areas. Average Body Surface area of a man is given as;

BSA $=1.9 \mathrm{~m}^{2}$

Average Body Thickness,

$\begin{array}{lll}\mathrm{ABT} & =23.75 \mathrm{~cm} \\ \mathrm{ABT} & =\mathrm{e}_{1}=0.24 \mathrm{~m}\end{array}$

Vertical clearance between HV and LV conductors as given in figure 6 is,

$\mathrm{h}_{1} \quad=\quad 1.4 \mathrm{~m}$

ii. From Magnetic Field point of view, it has been stated earlier in this write-up that Magnetic field induces a voltage in the tissue of human body, which causes a current to flow through it due to its conductivity. There are three established basic coupling mechanisms through which time-varying electric and magnetic fields interact directly with living matter.

$>$ Coupling to low-frequency electric fields:- which leads to electric current, formation of electric dipoles and reorientation of electric dipoles already present in the tissue. 
$>$ Coupling to low-frequency magnetic fields:which lead to induced electric fields and circulating electric current.

$>$ Absorption of energy from electromagnetic fields:- resulting into highly non-uniform deposition and distribution of energy within the body.

The first two cases are our point of concentration.

The physical interaction of time-varying magnetic fields with the human body results in induced electric fields and circulating electric currents. At low frequencies, the magnetic and electric fields are decoupled. The exact path and magnitude of the resulting current induced in any part of the body will depend on the electrical conductivity of the tissue.

Exposure to time-varying electric and magnetic fields result in induction of internal body current, and the known adverse effects are associated with nerve excitation. The primary dosimetric measure is the local induced electric field. This measure is selected because thresholds of the excitable tissue stimulation are defined by the electric field and its spatial variation. However, current density is used in some exposure guidelines. Among the measurements often reported are the average, root mean square (rms) and maximum induced electric field and current density values

Current density estimation at the head region will be considered by using magnetic field model by assuming that the body has a homogenous and isotropic conductivity and current path is circular [15].An assessment of human exposure toextremely-low-frequency (ELF) electric field generated by a power line is usually made using the rotationally-cylindrical body model [16].The model for the estimation of current density at the head region uses the following equation derived based on the formulation of faraday's law of induction. Basic equation related with a magnetic fields induction current analysis are as follows.

$$
\begin{gathered}
\nabla \times B=j \omega \\
\nabla . J=j \omega \\
J=\sigma E \\
J=\pi R f \sigma B
\end{gathered}
$$

Also, by Lorentz force law,

$$
\mathbf{F} \quad=\quad \mathbf{q}(\mathbf{E}+\mathbf{v} \times \mathbf{B})
$$

Where $\mathbf{E}=$ induced electric field, $\mathbf{B}=$ magnetic flux density, $\omega=$ angular frequency, $\sigma=$ conductivity, $\mathbf{R}=$ radius of loop $(\mathrm{m}), \mathrm{f}=$ power-line frequency $\mathbf{J}=$ induction current density, a force $\mathbf{F}, \mathbf{v}$ is the particle's velocity,and time differential is transformed into $\mathbf{j} \omega$.
For a point $\mathbf{P}$ on the axis of a closed circular current loop with radius $\mathbf{R}$, the total induced field $\mathbf{B}$ can be obtained as:

$$
B=\frac{\mu_{0}}{2 \pi} i \frac{\pi R^{2}}{r^{3}}=\frac{\mu_{0}}{2 \pi} \frac{|\mathbf{m}|}{r^{3}}
$$

Where, dipole moment $\mathbf{m}$ is associated with the current loop with a magnitude of $|\mathbf{m}|=\pi \mathbf{R}^{2} \mathbf{i}$ i.e. the current times the area enclosed by the loop. This shows the spatial attenuation of the field as 1 over distance cubed.

In the estimation of induced current density in the head region, at extremely low frequency, tissues conductivities $\sigma$ are of the order of $0.2 \mathrm{~S} / \mathrm{m}$ while a radius Rof 0.075 meters of the induction loop are assumed for the head and a maximum Magnetic Field Strength B of 100mG $(10 \mu \mathrm{T})$ was measured in a substation location in Nigeria (Ocheni Abdullahi Usman and Adam Usman) [7]. For a human being in such environment, the current density is evaluated from equation (4) above:

$$
\begin{array}{ll}
\Rightarrow \mathrm{J} & =\quad \pi * 0.075 * 50 * 0.2 * 0.00001 \\
= & 23.562 \times 10^{-6} \mathrm{~A} / \mathrm{m}^{2}
\end{array}
$$

If the average height of a normal human being is $\mathbf{h}_{\mathbf{B}}=\mathbf{1 . 7 5 m}$ and the height of the HV line as earlier discussed is $\mathbf{h}_{\mathbf{P}}=$ $\mathbf{8 . 5} \mathrm{m}$ above ground level, then the clearance of the HV line to the head of our model on ground in this calculation is given by;

$$
\begin{array}{llll}
\mathbf{r} & = & \mathbf{h}_{\mathrm{P}}-\mathbf{h}_{\mathrm{B}}= & 6.75 \mathrm{~m} \\
\mu_{0} & = & 4 \pi \times 10^{-7}
\end{array}
$$

Therefore, from equation (6);

$$
\begin{array}{lll}
\mathbf{B} & = & \left(4 \pi \times 10^{-7} \times \mathrm{m}\right) /\left(2 \pi \times 6.75^{3}\right) \\
10 \mu \mathrm{T} & = & 6.50 \times 10^{-10} \times \mathrm{m} \\
\mathbf{m} & = & \begin{array}{l}
\mathbf{0 . 0 0 0 0 1 0} / 6.50 \times 10^{-10} \\
\text { (current dipole moment) }
\end{array} \\
& = & 15.38 \mathrm{KA}-\mathrm{m}^{2}
\end{array}
$$

Now, as was seen in earlier discussions, the distance between the $\mathrm{HV}$ and $\mathrm{LV}$ point of incidence is $\mathbf{r}=\mathbf{1 . 4 m}$, given that the $\mathrm{HV}$ and LV terminals form two parallel plate Dipole terminals. Assuming that the man is operating within least distance of distinct vision (LDDV) or the reference seeing distance (RSD) which is about $25 \mathrm{~cm}$ from the eye, at angle $45^{\circ}$ (33\% of his height is above line of distinct vision), twothirds of his body trunk must be below the LV line of vision.

$\begin{array}{llll}\mathbf{r} & = & 1.4-(0.33 \times 1.75) \\ & = & 0.8225 \mathrm{~m} \\ \Rightarrow \mathrm{B} & = & \left(4 \pi \times 10^{-7} \times 15380\right) /\left(2 \pi \times 0.823^{3}\right) \\ & = & 0.00553 \mathrm{~T} \\ \mathrm{~B} & = & 5.53 \mathrm{mT}\end{array}$


Assuming average body trunk radius of $\mathrm{R}=0.165 \mathrm{~m}$

$\begin{array}{lll}\mathrm{J} & = & \pi * 0.165 * 50 * 0.2 * 0.00553 \\ & = & 0.0287 \mathrm{~A} / \mathrm{m}^{2} \\ \mathrm{~J} & = & 28.7 \mathrm{~mA} / \mathrm{m}^{2}\end{array}$

We will now compare these values with the effect of magnetic field exposure limits given on table 10 below:

Table 10: Magnetic Field Exposure Effect

\begin{tabular}{|l|l|}
\hline $\begin{array}{l}\text { Electric current density }\left(\mathrm{mA} / \mathrm{m}^{2}\right) \\
(\text { at } 50 / 60 \mathrm{~Hz})\end{array}$ & \multicolumn{1}{|c|}{ Effect } \\
\hline $\begin{array}{l}1 \text { to } 10 \\
(500 \text { to } 5,000 \mu \mathrm{T})\end{array}$ & $\begin{array}{l}\text { Minor biological effects have been } \\
\text { reported. }\end{array}$ \\
\hline $\begin{array}{l}10 \text { to } 100 \\
(5,000 \text { to } 50,000 \mu \mathrm{T})\end{array}$ & $\begin{array}{l}\text { There are well established effects, } \\
\text { including visual and nervous system } \\
\text { effects. } \\
\text { Facilitation of bone fracture reunion } \\
\text { has been reported. }\end{array}$ \\
\hline $\begin{array}{l}100 \text { to } 1,000 \\
(50,000 \text { to } 500,000 \mu \mathrm{T})\end{array}$ & $\begin{array}{l}\text { Stimulation of excitable tissue is } \\
\text { observed and there are possible } \\
\text { health hazards. }\end{array}$ \\
\hline$>1,000$ & $\begin{array}{l}\text { Extra systoles and ventricular } \\
\text { fibrillation, i.e., acute health hazards, } \\
\text { have been established. }\end{array}$ \\
\hline $500,000 \mu \mathrm{T})$
\end{tabular}

We can conclude here that there is magnetic field strength of $5,530 \mu \mathrm{T}$, and Current densityof $28.7 \mathrm{~mA} / \mathrm{m}^{2}$ circulating within his body. Going by the provisions of table 13 , this falls within cases of a well establishedmagnetic field effect of visual and nervous system breakdown.

iii. Exposure to these fields in turn induces fields and currents inside the body. If only the induced electric field and resultant current density in tissues and cells are considered, as the internal magnetic field in tissues and cells is the same as the external field. At extremely low frequencies, exposure is characterized by the electric field strength (E) or the electric flux density (also called the displacement) vector (D), and the magnetic field strength $(\mathrm{H})$ or the magnetic flux density (also called the magnetic induction) (B)

The induced AC current density $\left(\boldsymbol{J}_{A C}\right)$ at victim's bodymass is a function of the induced voltage on victim $\left(\boldsymbol{V}_{I N D}\right)$, body resistivity $\left(\boldsymbol{\rho}_{B}\right)$, and body thickness $\left(\boldsymbol{e}_{1}\right)$. Based on our earlier assumption of cylindrical anatomical structure of the body mass, it can be computed as follows:Using the limiting values on table 12 below, the reason for the electrocution is very obvious. The limit for professionally trained workers (Competent Persons) is $20 \mathrm{KV} / \mathrm{m}$.

Table 11: ICNIRP, the EU Recommendation, and the Control of Electro-magnetic Fields at Work Regulations

\begin{tabular}{|l|l|l|}
\hline Public exposure & magnetic & $360 \mu \mathrm{T}$ \\
\hline & electric & $9 \mathrm{kV} / \mathrm{m}$ \\
\hline $\begin{array}{l}\text { Occupational exposure (High Action } \\
\text { Level) }\end{array}$ & magnetic & $\begin{array}{l}6000 \\
\mu \mathrm{T}\end{array}$ \\
\hline & electric & $\begin{array}{l}20 \\
\mathrm{kV} / \mathrm{m}\end{array}$ \\
\hline
\end{tabular}

$\mathbf{J}_{\mathrm{AC}}=\underline{\mathbf{8 .}} \underline{\mathbf{V}}_{\underline{\mathbf{I N D}}}$

$\rho_{B} \cdot \pi \cdot e_{1}$

Knowing that, $\quad \rho_{B}=R S / L$

Using the parameters for an average man, the conducting part between head and feet can be approximated as a cylinder $1.75 \mathrm{~m}$ long and surface area of $1.9 \mathrm{~m}^{2}$.

$\begin{array}{lll}\mathbf{S} & = & 1.9 \mathrm{~m}^{2}(\text { body surface area }) \\ \mathbf{L} & = & 1.75 \mathrm{~m} \\ \mathbf{R} & = & 1100 \Omega(\text { assuming conducting part } \\ & & \text { between head and feet }) \\ \Rightarrow \rho_{B} & = & 1100 * 1.9 / 1.75 \\ = & 1,194.29 \Omega-m\end{array}$

Consider half of the above calculated induced voltage

$$
\begin{array}{rlll} 
& \mathrm{V}_{\mathrm{IND}} & = & 6.072 \mathrm{kV} \\
\therefore \quad & \mathbf{J}_{\mathrm{AC}} & = & \mathbf{8} * \mathbf{6 , 0 7 2 / 1 1 9 4 . 2 9} * \pi * \mathbf{0 . 2 4} \\
& & = & \mathbf{5 3 . 9 4 A} / \mathbf{m}^{2}
\end{array}
$$

Again, if tissues conductivities $\sigma$ are of the order of $0.2 \mathrm{~S} / \mathrm{m}$ and a radius Rof 0.075 meters of the induction loop are assumed for the head, with induced current of at least $100 \mathrm{~mA}$;

$$
\begin{aligned}
& \Rightarrow \mathbf{I}_{\mathrm{AC}}=\mathbf{S}_{\mathrm{h}} * \mathbf{J}_{\mathrm{AC}} \\
& \mathrm{J}_{\mathrm{AC}}=100 \times 10^{-3} /\left(\pi^{*} 0.0750^{2}\right) \\
& \begin{array}{llll} 
& = & 5.66 \mathrm{~A} / \mathrm{m}^{2} & \\
\mathrm{E} & = & 5.66 / 0.2= & 28.3 \mathrm{kV} / \mathrm{m}
\end{array}
\end{aligned}
$$

Two of fewdetermining factors of electric field intensity at the surface of the body and induced currents passing through various segments of the body are:

a) The location of the body relative to ground and other conductors; and

b) Any conduction currents from the body to ground or other conductors.

A body is coupled to an electric field in proportion to its capacitance such that the greater the capacitance the greater the current flow in the body. Human beings have capacitances of about $125 \mathrm{pF}$, when in close proximity with ground [18]. We now turn our attention to the capacitance component of the victim.

We shall assume here that the victim is so close to or even in direct contact with the transformer LV terminals that it can be taken as direct return path to earth. Therefore, only the body capacitance and the transformer LV inductive network apply as shown in figure 17 below. 


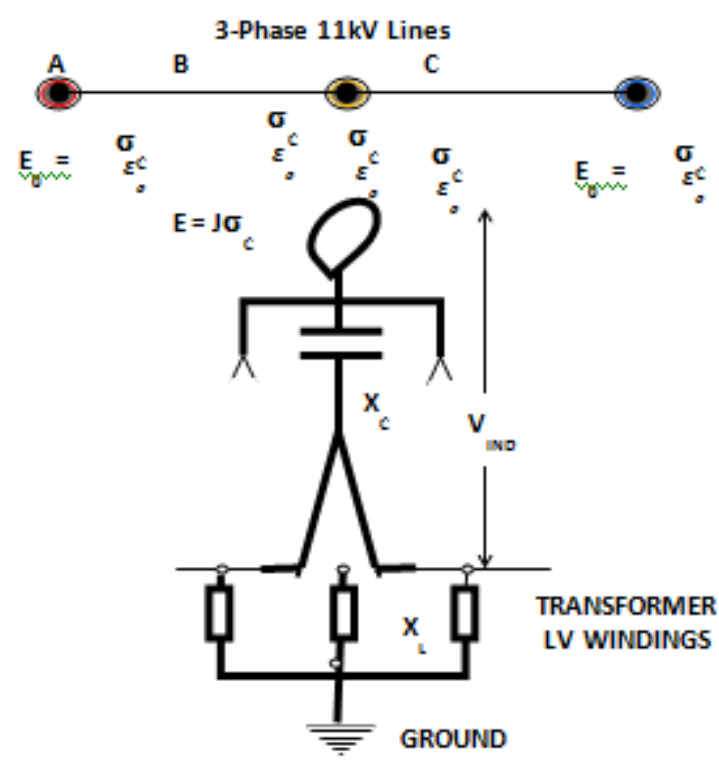

Fig 17: Capacitive Link to Ground through Victim.

From the diagram;

$$
\begin{array}{rlll}
\mathbf{X}_{\mathrm{C}} & = & 1 / \mathrm{j} \omega \mathrm{C}=1 /(2 \pi \mathrm{fC}) \\
& = & 1 /\left(2 \pi * 50 * 125 \times 10^{-9}\right) \\
& = & 25,464.791 \Omega
\end{array}
$$

$\mathbf{X}_{\mathbf{L}}$ is calculated from the transformer Impedance Voltage. Typical Impedance Voltage rating for a 0-630KVA Distribution Transformer is given by;

$$
\mathrm{X}_{\mathrm{T}} \%=\mathbf{4 . 0}-\mathbf{4 . 5} \%
$$

We will assume $\mathbf{X}_{\mathrm{T}} \boldsymbol{\%}=\mathbf{4 . 5 \%}=\mathbf{0 . 0 4 5 p u}$, for a 500KVA transformer

$$
\begin{aligned}
\Rightarrow \quad \mathbf{X}_{\mathrm{T}}= & \left(0.045 \times(\text { base } \mathrm{kV})^{2}\right) /(\text { base } \mathrm{kVA} \times 1000) \\
& =\quad\left(0.045 * 11^{2}\right) /(500 * 1000) \\
& =10.89 \times 10^{-6} \Omega
\end{aligned}
$$

It is obvious from this evaluation that only the capacitive reactance is significant and the entire current flow to ground will be based on.

Therefore, if we assume of $6.072 \mathrm{kV}$ as before, Actual current passing through the body is given by;

This

$$
\begin{array}{rlr}
\mathbf{I}_{\mathrm{AC}} & = & \mathbf{V}_{\text {IND }} / \mathbf{X}_{\mathrm{C}} \\
& = & \mathbf{6 , 0 7 2 / 2 5 , 4 6 4 . 7 9 1} \\
& = & \mathbf{0 . 2 3 8 4 A} \\
& = & \mathbf{2 3 8 m A}
\end{array}
$$

From standard tables of electrocution effects, this results in Ventricular Fibrillation maximum Threshold and will tend towards Cardiac Standstill.

\section{CONCLUSION}

From the analysis conducted on this case-study and the results of our electromagnetic evaluations, it is here concluded that the lethality of electrocutions resulting from electromagnetic fields in electric power distribution systems are largely due to violation of approach limits within the electric field. It was established that the human structure in the vicinity of electromagnetic field transforms into a dielectric material (human dielectric), resulting into significant electric field influence that caused electrocutions.

\section{ACKNOWLEDGEMENT}

I wish at this point to express my gratitude to Engr. Solomon Uwaifo, a veteran octogenarian Power Distribution Expert, who ignited my interest and gave me an opportunity to express myself in his online technical magazine - Electricity in Nigeria (EIN). I will also not forget my professional colleague, Engr. DauduAbdulaziz, the MD CEO Shiroro Power Generating Company, who remembered and introduced me when the need arose for a discussion on this subject.

\section{REFERENCES}

[1] FLAVIUS DAN SURIANU, "Determination of the Induced Voltages by $220 \mathrm{kV}$ Electric Overhead Power Lines Working in Parallel and Narrow Routes. Measurements on the Ground and Mathematical Model.,,WSEAS Transactions on Power Systems, Issue 8, Volume 4, August 2009,264-274.

[2] PASCOE, K. J.,"Properties of Materials for Electrical Engineers”, John Wiley \& Sons, 1974

[3] Pailler-Mattei, C., Guerret-Piécourt, C., Zahouani, H., Nicoli, S., "Interpretation of the human skin biotribological behaviour after tape stripping”,Journal of the Royal Society Interface, Published 12 January 2011. DOI: 10.1098/rsif.2010.0672,

[4] Paul I. Audu, "The Problem of Frequent Electrocution Incidences In Nigeria - Causes And Solution (Part 2)"Electricity in Nigeria (EIN), September, 2016,http://electricityinnigeria.com/ein-magazine.

[5] TakaakiMusha,"Metamaterial Structure Inside Microtubles of the Human Brain May Explain Advanced Brain Performance.”, American Journal of Optics and Photonics, Sep. 20, 2015,

[6] U.S. Department of Energy, "DOE HANDBOOK ELECTRICAL SAFETY”, DOE-HDBK-1092-2013, July 2013,

[7] Ocheni Abdullahi Usman, Adam Usman, "Assessment of Magnetic Field Effects and Estimation of Associated Current Density of Electrical Injection Substations in Kano Metropolis", Advances in Physics Theories and Applications, www.iiste.org ISSN 2224719X (Paper) ISSN 2225-0638 (Online) Vol.50, 2015, 
[8] Un-identified author, "ELECTRIC FIELDS AND CHARGE", www.physics.usyd.edu.au/super /life sciences/E/E-all, Lecture Notes.

[9] Anirudh Balaji, "Effect of High Voltage Transmission Lines on Human Health, Plant Life, and Animal Activity", International Research Journal of Engineering and Technology (IRJET) e-ISSN: 23950056, p-ISSN: 2395-0072 Volume: 02 Issue: 03 | June-2015,

[10] Karpov, Victor, G., "Chapter 22: The Electric Field", Department of Physics and Astronomy, University of Toledo, Toledo, Ohio, United States. Lecture notes vkarpov@physics.utoledo.edu.

[11] J. Michael Griggs, "Human Figure average measurements", Loebinfo.com,copyright (C) 2001,

[12] Suk Won Min, EungSik Kim, Sung Ho Myung, "Calculation and Measurement of Induced Current Density Inside Human Body Under $60 \mathrm{~Hz}$ ELF Magnetic Fields", EMC'09/Kyoto, Copyright (C) 2009 IEICE.

[13] M'hamedOuadah, Omar Touhami1, and Rachid Ibtiouen, "Diagnosis of the AC Current Densities Effect on the Cathodic Protection Performance of the Steel X70 for a Buried Pipeline due to Electromagnetic Interference Caused by HVPTL", Progress In Electromagnetics Research M, Vol. 45, 163-171, 2016.

[14] R. D. Southey, F. P. Dawalibi,"Conduction of Electrical Current to and Through the Human Body: A Review",Safe Engineering Services \& Technologies Ltd, 1544 Viel,

[15] Riccardo Scorretti, No $\square$ lBurais, Laurent Nicolas, Alain Nicolas, "Modeling of induced current into the human body by low-frequency magnetic field from experimental data" IEEE Transactions on Magnetics, Institute of Electrical and Electronics Engineers, 2005, 41 (5), pp.1992-1995.

[16] AbdelmalekLaissaoui, BachirNekhoul, Kamal Kerroum,Khalil El KhamlichiDrissi, and Dragan Poljak, "On the Rotationally-Cylindrical Model ofthe Human body exposed to ELF ElectricField", Progress In Electromagnetics Research M, Vol. 29, 165\{179, 2013,.

[17] Montreal, Quebec, Canada, H3M 1G4. E-mail: info@sestech.com, “Computer Modelling of AC Interference Problems for the most Cost-effective Solutions".

[18] World Health Orgnization Geneva, 1984, "Environmental Health Criteriafor Extremely Low Frequency (ELF) Fields" International Programmeon Chemical Safety, Geneva, 1984 Reprinted 1992 ISBN 9241540958

[19] National Institute for Occupation Safety \& Health: Worker Deaths by Electrocution (http://www.cdc.gov/niosh/ docs/ 98131/), a CDC study

\section{BIOGRAPHIE}

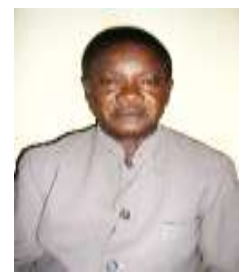

Engr. Paul I. Audu graduated from Ahmadu Bello University (A.B.U), Zaria with a B.Eng.(Hons) degree in Electrical Engineering in July, 1980. He has practiced in the field of Power System Protection \& Control for over Thirty-eight years (38 years). 